
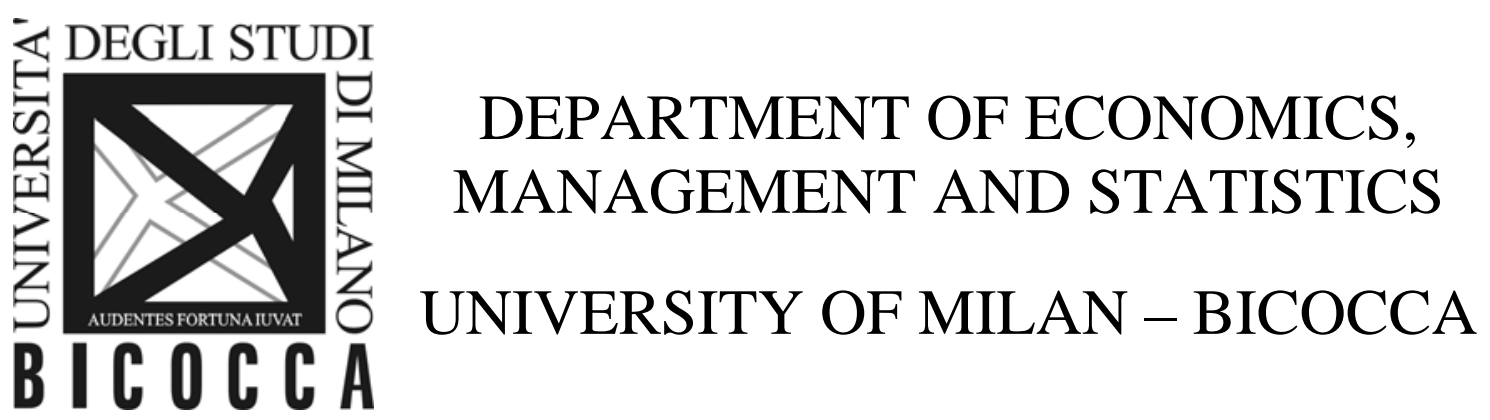

DEMS WORKING PAPER SERIES

The Equity Premium in a DSGE Model with Limited Asset Market Participation

Lorenzo Menna, Patrizio Tirelli

No. 275 - June 2014

Dipartimento di Economia, Metodi Quantitativi e Strategie di Impresa

Università degli Studi di Milano - Bicocca

http://dems.unimib.it/ 


\title{
The Equity Premium in a DSGE Model with Limited Asset Market Participation
}

\author{
Lorenzo Menna* Patrizio Tirelli ${ }^{\dagger}$
}

June 17, 2014

\begin{abstract}
Models based on the representative agent assumption cannot rationalize observed equity premia. In response to this, exchange economy models have introduced agents heterogeneity, typically in the form of bond and equity holders. We reconsider the issue introducing Limited Asset Market Participation in an otherwise standard medium scale DSGE model. Our model fits financial and macroeconomic data well. We obtain that the correlation between asset holders consumption and financial returns strongly increases in the share of agents excluded from financial markets participation, The predicted unconditional equity premium is therefore large. Further, the strong correlation between dividends and Ricardian households' consumption unambiguously increases precautionary savings and reduces the riskless rate.

Jel codes: E32 G12

Keywords: asset pricing, equity premium, limited asset market participation, business cycle, DSGE, sticky prices.
\end{abstract}

\section{Introduction}

The standard neoclassical finance model based on intertemporal consumption optimization predicts that assets are priced according to their correlation with aggregate consumption growth, but this latter variable is apparently too smooth for the model to replicate the empirically observed equity premium (Mehra and Prescott, 1985). In response to this, and to other related "puzzles", the production-based asset pricing literature has explored the connection between the stylized facts of the business cycle and the empirical regularities that characterize the financial markets, such as the equity premium, its Sharpe ratio, the risk-free rate and return autocorrelations. Lettau (2003), Jermann (1998), Boldrin, Christiano and Fischer (2001) and Uhlig (2007), have shown that the predicted unconditional risk premium increases if one extends the real business cycle model to account for real frictions. De Paoli, Scott and Weeken (2010) find that nominal rigidities increase the unconditional premium in case of aggregate demand shocks and decrease it in case of aggregate supply shocks. Nevertheless, these models still find it difficult to replicate the relatively large risk premia observed in the data.

\footnotetext{
${ }^{*}$ Lorenzo Menna, University of Milano-Bicocca, Piazza dell'Ateneo Nuovo, 120100 Milano, Italy. Email: lorenzo.menna@unimib.it

${ }^{\dagger}$ Prof. Patrizio Tirelli, University of Milano-Bicocca, Piazza dell'Ateneo Nuovo, 120100 Milano, Italy. Email: patrizio.tirelli@unimib.it
} 
Another strand of literature has considered rudimentary real business cycle models where only a subset of households participate in the stock exchange market but access to the bonds market is unrestricted. In this framework shareholders provide partial income insurance to bond holders and, relative to the case of full stock market participation, the concentration of firms capital in their hands raises the correlation between their consumption growth rate and stock returns. This finding is consistent with empirical evidence suggesting that the consumption of stockholders is more volatile than that of non-stockholders and is more highly correlated with the excess return on the stock market (Mankiw and Zeldes, 1991). Polkovnichenko (2004) shows that restricting asset market participation cannot warrant a sufficiently large increase in the theoretical risk premium. In a similar framework, Guvenen (2009) assumes that stock holders are characterized by a relatively large elasticity of intertemporal substitution in consumption. His model can replicate the empirical facts concerning financial variables but predicts excessive volatility in consumption growth and in the labor supply. In addition, the embryonic production side of the model economy does not allow to disentangle the effects of different shocks and frictions in determining financial variables.

This paper is inspired by Weil (1992), who showed that Limited Asset Market Participation (LAMP henceforth) may contribute to solve the empirical equity premium puzzle in endowment models. The LAMP hypothesis implies that only a fraction of consumers participate in financial markets whereas the rest of the population, i.e. the rule-of-thumb or hand-to-mouth consumers (RT consumers, henceforth), do not accumulate any wealth and entirely consume their current income. Here we show that the LAMP hypothesis, already popularized in DSGE models (Galì et al., 2007), allows to strongly improve the fit of the unconditional moments of financial variables in an otherwise standard DSGE model, akin to Smets and Wouters (2007). A number of studies estimate the fraction of RT consumers in a range between 26\% and 50\%. (Campbell and Mankiw, 1990; Iacoviello, 2004; Coenen and Straub, 2005; Forni, Monteforte, and Sessa, 2009).

In a nutshell, the key message of the paper is that DSGE models characterized by the LAMP hypothesis can replicate key moments of financial variables, while improving over the corresponding representative agent model for what concerns the fit of macroeconomic moments at business cycle frequency. In our model the equity premium essentially arises due to a combination of price stickiness and LAMP. In fact sticky prices cause a redistribution of factor incomes whenever shocks hit the economy. For instance a positive productivity shock raises firms profits and lowers labor incomes (in analogy with the findings in Smets and Wouters, 2007 and in references cited therein). If wealth is concentrated in the hands of relatively few investors, i. e. the proportion of RT consumers is sufficiently large, the resulting strong correlation between stockholders consumption and profits is sufficient to predict an empirically plausible risk premium. In addition, the large effect of dividends volatility on the standard deviation of Ricardian households' consumption unambiguously increases the precautionary savings and reduces the riskless rate. Thus LAMP greatly improves model fit of both the equity premium and the riskless rate.

Our characterization of the LAMP hypothesis is quite different from De Graeve et al. (2010) who use LAMP to rationalize the risk premia in a DSGE model with flexible prices. Their model economy is populated by three household groups, shareholders, bondholders and workers who do not hold any wealth. The relatively more risk averse workers engage in long term labour contracts with firms. Such contracts generate endogenous wage stickiness and allow mutual risk sharing between workers, bondholders and stockholders. Due to price flexibility and to the mechanism driving wage-setting contracts, the key mechanism generating the risk premium in their model is quite different from ours, where mutual risk sharing between stockholders and non- stockholders is precluded. In fact in their model the negative correlation between a workers' bargaining power shock 
and the productivity shock is necessary to obtain the covariance between stockholders consumption growth and equity returns which is necessary to replicate risk premiums. This happens because the optimal labour contract they consider does not allow the model to endogenously produce a significant redistribution among agents. One of the most important contributions of this paper is to demonstrate that it is exactly the uninsurable income redistribution generated by the shocks that increases the equity premium in a DSGE model.

We consider two key shocks, an investment specific shock and a TFP shock. In particular, we find that the equity premium is mainly determined by TFP shocks, while investment specific shocks are fundamental to replicate the volatility of other macro data. LAMP and sticky prices are necessary in such a setting because they allow to extract a higher equity premium from a less volatile TFP shock and to fit macro data more easily. We also find that LAMP overturns the result in De Paoli et al (2010) that sticky prices reduce the risk premium generated by supply shocks. This latter result is determined by the redistributive effects of supply shocks that, due to sticky prices, cause a fall in labor demand and in the real wage, thereby inducing a positive correlation between profits and the consumption of asset holders.

The remainder of the paper is organized as follows. Section 2 presents and derives the model. Section 3 presents the impulse responses and the simulation results. Section 4 checks the robustness of the results and runs the sensitivity analysis. Section 5 draws the conclusions and the perspectives for future research.

\section{The Model}

The key distinction between asset holders and RT consumers concerns intertemporal optimization of consumption decisions. Asset holders take into account future utility when choosing consumption and portfolio composition. RT consumers spend their whole income every period, thus they do not hold any wealth.

Most papers concerned with financial market outcomes use utility specifications which are nonstandard in the DSGE literature, where log-utility in consumption is typically adopted. This utility characterization implies coefficients of consumption risk aversion and intertemporal substitution which are coincident and equal to one. Risk aversion must be larger than one to fit the risk premiums, but in a standard separable utility specification this would compromise the dynamic performance the macroeconomic model, due to the fall in the elasticity of intertemporal substitution and to the much larger wealth effect on labour supply. To avoid these shortcomings, several studies adopt the Epstein Zin format, which allows to disentangle risk aversion from the elasticity of intertemporal substitution (Rudebusch and Swanson, 2011; Binsberger et al., 2010). As an alternative, De Graeve et al. (2010) use the Greenwood Hercowitz Huffman (GHH) utility specification, which eliminates any wealth effect from labour supply.

Here we adopt a King-Plosser-Rebelo (KPR) utility specification, with external consumption habits. KPR utility incorporates log-separable utility as a special case, maintains the wealth effect on labour supply equal to one for any level of relative risk aversion and is compatible with a balanced growth path. Instead of the more standard habit-in-difference specification, we are going to consider the habit-in-ratio specification presented in Abel (1988). The reason for this is that under LAMP external habits in difference can easily generate a negative marginal utility of consumption for RT households. The ratio format allows to avoid this problem. Right from the outset, it should be noted that the non-saparability and the habit-in-ratio assumptions play no role in determining our key results. 
In order to solve the model, we make use of the second-order perturbation methods developed by Schmitt-Grohe and Uribe (2004), that allow risk to affect the value of variables in steady state and to study unconditional risk premia. ${ }^{1}$

\subsection{Households}

We assume a continuum of households indexed by $i, i \in[0,1]$. RT consumers (rt ) and assetholders or Ricardian consumers $(o)$ are defined over the intervals $[0, \psi]$ and $(\psi, 1]$ respectively. All households share the same KPR utility function:

$$
U\left(c_{t}^{i}, n_{t}^{i}\right)=\frac{1}{1-\sigma}\left(\frac{c_{t}^{i}}{c_{t-1}^{\chi}}\left(1-\theta\left(n_{t}^{i}\right)^{\phi}\right)\right)^{1-\sigma}
$$

where $n_{t}^{i}=\left[\int_{0}^{1}\left(n_{h, t}^{i}\right)^{\frac{\nu-1}{\nu}} d h\right]^{\frac{\nu}{\nu-1}}$ defines the labor bundle and $c_{t}^{i}$ is the consumption good. In the following we shall assume that $\sigma>1$. Note that this is necessary to capture the spirit of the catching up with the Joneses specification, that is, a coeteris paribus increase in the habit term raises the marginal utility of consumption $U_{c}\left(c_{t}^{i}, n_{t}^{i}\right) .^{2}$

\subsubsection{Ricardian households}

The representative Ricardian household has access to financial markets and maximizes her lifetime discounted utility subject to the budget constraint

$$
P_{t} c_{t}^{o}+V_{t}^{N} B_{t}^{N, o}+v_{t}^{R} P_{t} B_{t}^{R, o}+V_{t}^{e q} S_{t}^{o} \leq W_{t} n_{t}^{o}+B_{t-1}^{N, o}+B_{t-1}^{R, o} P_{t}+\left(V_{t}^{e q}+D_{t}\right) S_{t-1}^{o}
$$

where total dollar expenditures in the consumption good $\left(P_{t} c_{t}^{o}\right)$, in nominal bonds $\left(V_{t}^{N} B_{t}^{N, o}\right)$, in indexed bonds $\left(v_{t}^{R} P_{t} B_{t}^{R, o}\right)$ and in equity shares $\left(V_{t}^{e q} S_{t}^{o}\right)$ must not exceed total dollar revenues, given by the sum of labor income $\left(W_{t} n_{t}^{o}\right)$, nominal bonds $\left(B_{t-1}^{N, o}\right)$, indexed bonds $\left(B_{t-1}^{R, o} P_{t}\right)$ and the payoff of equity $\left(\left(V_{t}^{e q}+D_{t}\right) S_{t-1}^{o}\right)$. Note that $V_{t}^{N}, V_{t}^{e q}, P_{t}$, respectively define the dollar prices of nominal bonds, of the equity index and of the consumption good; whilst $v_{t}^{R}$ defines the real price of the indexed bond. $W_{t}$ defines the nominal wage, $D_{t}$ is the nominal dividend payment received from owned firms. The household chooses consumption, nominal bonds, indexed bonds and equity holdings while delegating the wage choice to a union. As in De Paoli et al (2010), Ricardian households do not invest directly in capital. Investment in capital is carried out at the level of the intermediate firms. Hence dividends contain both extra-profits deriving from monopolistic competition and the normal return on capital. The first order conditions of the problem are:

$$
\lambda_{t}^{o}=\left(c_{t}^{o}\right)^{-\sigma}\left(\frac{1-\theta n_{t}^{\phi}}{c_{t-1}^{\chi}}\right)^{1-\sigma}
$$

\footnotetext{
${ }^{1}$ Allowing for time-varying risk premia would require third order perturbation and is outside the scope of this paper.

${ }^{2}$ Here, as in the rest of the paper, lower case letters denote variables expressed in real terms.
} 


$$
\begin{gathered}
V_{t}^{e q}=\beta E_{t}\left(\frac{\lambda_{t+1}^{o}}{\lambda_{t}^{o}} \frac{V_{t+1}^{e q}+D_{t+1}}{\pi_{t+1}}\right) \\
v_{t}^{R}=\beta E_{t}\left(\frac{\lambda_{t+1}^{o}}{\lambda_{t}^{o}}\right) \\
V_{t}^{N}=\frac{1}{R_{t}^{N}}=\beta E_{t}\left(\frac{\lambda_{t+1}^{o}}{\lambda_{t}^{o}} \frac{1}{\pi_{t+1}}\right) \\
c_{t}^{o}=w_{t} n_{t}+\frac{d_{t}}{1-\psi}
\end{gathered}
$$

where $\pi_{t}=\frac{P_{t}}{P_{t-1}}$ defines the inflation rate and $R_{t}^{N}$ the nominal interest rate. The market clearing conditions for the equity and bonds markets are:

$$
\begin{gathered}
S_{t}^{o}(1-\psi)=1 \\
B_{t}^{N, o}(1-\psi)=0 \\
B_{t}^{R, o}(1-\psi)=0
\end{gathered}
$$

\subsubsection{RT Households}

RT households do not optimize and simply consume their labor income each period. Their budget constraint is $P_{t} c_{t}^{r t}=W_{t} n_{t}$. The marginal utility of consumption for RT households is:

$$
\lambda_{t}^{r t}=\left(c_{t}^{r t}\right)^{-\sigma}\left(\frac{1-\theta n_{t}^{\phi}}{c_{t-1}^{\chi}}\right)^{1-\sigma}
$$

\subsection{Aggregation among households}

Average marginal utility and aggregate consumption respectively are

$$
\begin{aligned}
\lambda_{t} & =\psi \lambda_{t}^{o}+(1-\psi) \lambda_{t}^{r t} \\
c_{t} & =(1-\psi) c_{t}^{o}+\psi c_{t}^{r t}
\end{aligned}
$$

\subsection{Unions}

There is one labour union for each differentiated labor type. The representative labour union solves the following problem: ${ }^{34}$

\footnotetext{
${ }^{3} \mathrm{We}$ assume that the nominal wage adjustment cost is intangible. In section 2.5 we make the same assumption for the price adjustment cost, following De Paoli et al (2010). In a separate exercise, we solved the model with tangible nominal adjustment costs and found that our results are unaffected. The assumption that wage adjustment costs are intangible implies that such costs appear in the budget constraints of agents when unions solve their problem but they do not appear in the problem households.

${ }^{4}$ In the problem below we implicitly define $n_{t}\left(W_{h, t}\right)=\int_{0}^{1}\left(\frac{W_{h, t}}{W_{t}}\right)^{-\nu} d h n_{t}^{d}$.
} 


$$
\begin{gathered}
\max E_{0} \Sigma_{t=0}^{\infty} \beta^{t}\left[(1-\psi) U\left(c_{t}^{o}, n_{t}\left(W_{h, t}\right)\right)+\psi U\left(c_{t}^{r t}, n_{t}\left(W_{h, t}\right)\right)\right] \\
\text { s.t. } \quad P_{t} c_{t}^{o}=\int_{0}^{1} W_{h, t}\left(\frac{W_{h, t}}{W_{t}}\right)^{-\nu} d h n_{t}^{d}+\frac{D_{t}}{1-\psi}-\frac{X}{2}\left(\frac{W_{h, t}}{W_{h, t-1}}-1\right)^{2} P_{t} n_{t}^{d} \\
P_{t} c_{t}^{r t}=\int_{0}^{1} W_{h, t}\left(\frac{W_{h, t}}{W_{t}}\right)^{-\nu} d h n_{t}^{d}-\frac{X}{2}\left(\frac{W_{h, t}}{W_{h, t-1}}-1\right)^{2} P_{t} n_{t}^{d}
\end{gathered}
$$

The first order condition is

$$
\begin{gathered}
-\frac{\psi U_{n}\left(c_{t}^{o}, n_{t}\right)+(1-\psi) U_{n}\left(c_{t}^{r t}, n_{t}\right)}{\lambda_{t}}=\frac{\nu-1}{\nu} w_{t}+\frac{X}{\nu}\left(\pi_{W, t} \pi_{t}-1\right) \pi_{W, t} \pi_{t} \\
-\beta E_{t}\left[\frac{\lambda_{t+1}}{\lambda_{t}} \frac{X}{\nu}\left(\pi_{W, t+1} \pi_{t+1}-1\right) \pi_{W, t+1} \pi_{t+1} \frac{n_{t+1}}{n_{t}}\right]
\end{gathered}
$$

where

$$
U_{n}\left(c_{t}^{i}, n_{t}\right)=-\left(1-\theta n_{t}^{\phi}\right)^{-\sigma}\left(\frac{c_{t}^{i}}{c_{t-1}^{\chi}}\right)^{1-\sigma} \theta \phi n_{t}^{\phi-1}: i=o, r t
$$

and $\pi_{W, t}$ is real wage inflation, that is $\frac{W_{t}}{W_{t-1}} \frac{1}{\pi_{t}}$. Notice that differently from the Calvo setting there is no wage dispersion in equilibrium, hence $n_{t}=n_{t}^{d}$.

\subsection{Labour packers}

Labour packers buy the differentiated labour types from unions and sell the aggregated labour bundle to intermediate goods firms. They maximize profits under a Dixit-Stiglitz production function and operate under perfect competition:

$$
\max W_{t} n_{t}^{d}-\int_{0}^{1} W_{h, t} n_{h, t} d h \quad \text { s.t. } n_{t}^{d}=\left[\int_{0}^{1} n_{h, t}^{\frac{\nu-1}{\nu}} d h\right]^{\frac{\nu}{\nu-1}}
$$

The first order conditions are:

$$
\begin{aligned}
& n_{h, t}=\left(\frac{W_{h, t}}{W_{t}}\right)^{-\nu} n_{t}^{d} \\
& n_{t}^{d}=\left[\int_{0}^{1} n_{h, t}^{\frac{\nu-1}{\nu}} d h\right]^{\frac{\nu}{\nu-1}}
\end{aligned}
$$

Equation (9) is the demand for labour of type h, already shown in section 2.3. Combining it with (10) one gets the wage index $W_{t}=\left(\int_{0}^{1} W_{h, t}^{1-\nu} d h\right)^{\frac{1}{1-\nu}}$. 


\subsection{Intermediate Goods Firms}

Intermediate firm producing good $z$ maximizes profits subject to a Cobb-Douglas production function and to a downward sloping demand function. It also invests, accumulates capital and is subject to a capital adjustment cost and to a productivity-augmented fixed cost of production (Justiniano and Primiceri, 2010), chosen so that profits are zero in steady state (Christiano et al (2005)). Finally, it is also subject to a Rotemberg nominal price adjustment cost $\frac{K}{2}\left(\frac{P_{Z, t}}{P_{Z, t-1}}-1\right)^{2} y_{t}$. Following the assumptions in De Paoli et al (2010), this cost is intangible, in the sense that it is not subtracted to households income but it does enter the price setting decision. The optimization problem is:

$$
\begin{gathered}
\max E_{0} \Sigma_{t=0}^{\infty} \beta^{t} \lambda_{t}^{o}\left[d_{Z, t}-\frac{K}{2}\left(\frac{P_{Z, t}}{P_{Z, t-1}}-1\right)^{2} y_{t}\right] \\
\text { st } D_{Z, t} \leq \frac{P_{Z, t}}{P_{t}} y_{Z, t}-w_{t} n_{Z, t}^{d}-i_{Z, t} \\
y_{Z, t} \leq A_{t}\left(n_{Z, t}^{d}\right)^{\alpha} k_{Z, t-1}^{1-\alpha}-e^{g} f c \\
y_{Z, t}=\left(\frac{P_{Z, t}}{P_{t}}\right)^{-\mu} y_{t} \\
k_{Z, t} \leq(1-\delta) k_{Z, t-1}+\digamma_{t} \omega\left(i_{Z, t}, k_{Z, t-1}\right) k_{Z, t-1}
\end{gathered}
$$

where the discount factor $\beta^{t} \lambda_{t}^{o}$ reflects the preferences of firms owners, i.e. the Ricardian households, $k_{Z, t}$ is firm owned capital, $A_{t}$ is the technology variable that grows at rate $g$ and is subject to $\operatorname{AR}(1)$ shocks, such that

$$
\begin{aligned}
& \log A_{t}=g+\log A_{t-1}+\eta_{t} \\
& \eta_{t}=\rho_{\eta} \eta_{t-1}+\varepsilon_{\eta, t}
\end{aligned}
$$

where $\varepsilon_{\eta, t}$ is i.i.d. $N\left(0, \sigma_{\eta}^{2}\right)$. and $\omega\left(i_{Z, t}, k_{Z, t-1}\right)=\frac{a_{1}}{1-\frac{1}{X^{K}}}\left(\frac{i_{Z, t}}{k_{Z, t-1}}\right)^{1-\frac{1}{X^{K}}}+a_{2}$ is the capital adjustment cost according to the specification in Jermann (1998) and Uhlig (2007). In this formulation, $X^{K}$ represents the elasticity of the investment to capital ratio with respect to Tobin's Q and the capital adjustment cost is a decreasing function of $X^{K} . \digamma_{t}$ represents an investment specific shock that affects the relative price of investment goods ${ }^{5}$ and follows the process

$$
\log \digamma_{t}=\rho_{\digamma} \log \digamma_{t-1}+\varepsilon_{\digamma, t}
$$

where $\varepsilon_{\digamma, t}$ is i.i.d. $N\left(0, \sigma_{\digamma, t}^{2}\right)$.

After aggregating among firms and noticing that all of them fix the same price, the first order conditions for the representative intermediate firm are:

$$
w_{t}=m c_{t} A_{t} \alpha n_{t}^{\alpha-1} k_{t-1}^{1-\alpha}
$$

\footnotetext{
${ }^{5}$ Furlanetto and Seneca (2013) investigate the effects of investment-specific shocks under LAMP.
} 


$$
\begin{gathered}
q_{t}=\frac{1}{\digamma_{t}\left(a_{1}\left(\frac{i_{t}}{k_{t-1}}\right)^{-\frac{1}{X^{K}}}\right)} \\
q_{t}=E_{t}\left\{\beta \frac { \lambda _ { t + 1 } ^ { o } } { \lambda _ { t } ^ { o } } \left(\begin{array}{c}
m c_{t+1} A_{t+1}(1-\alpha) n_{t+1}^{\alpha} k_{t}^{-\alpha} \\
\left.\left.+q_{t+1}\left[1-\delta+\digamma_{t+1}\left(\left(\frac{1}{1-\frac{1}{X^{K}}}-1\right) a_{1}\left(\frac{i_{Z, t}}{k_{t}}\right)^{1-\frac{1}{X^{K}}}+a_{2}\right)\right]\right)\right\} \\
m c_{t}=\frac{\mu-1}{\mu}+\frac{K}{\mu_{t}}\left(\pi_{t}-1\right) \pi_{t}-\beta E_{t}\left[\frac{\lambda_{t+1}^{o}}{\lambda_{t}^{o}} \frac{K}{\mu}\left(\pi_{t+1}-1\right) \pi_{t+1} \frac{y_{t+1}}{y_{t}}\right] \\
y_{t}=A_{t} n_{t}{ }^{\alpha} k_{t-1}^{1-\alpha}-e^{g} f c \\
k_{t}=(1-\delta) k_{t-1}+\digamma_{t} \omega\left(i_{t}, k_{t-1}\right) k_{t-1} \\
d_{t}=y_{t}-w_{t} n_{t}-i_{t}
\end{array}\right.\right.
\end{gathered}
$$

\subsection{Final good firms}

Final good firms operate under perfect competition. They aggregate differentiated goods produced by intermediate goods firms and maximize profits subject to a production function of the DixitStiglitz type. The optimization problem is

$$
\max P_{t} y_{t}-\int_{0}^{1} P_{Z, t} y_{Z, t} d z \quad \text { st } y_{t}=\left[\int_{0}^{1} y_{Z, t}^{\frac{\mu-1}{\mu}} d z\right]^{\frac{\mu}{\mu-1}}
$$

The first order conditions read as follows:

$$
\begin{aligned}
& y_{Z, t}=\left(\frac{P_{Z, t}}{P_{t}}\right)^{-\mu} y_{t} \\
& y_{t}=\left[\int_{0}^{1} y_{Z, t}^{\frac{\mu-1}{\mu}} d z\right]^{\mu-1}
\end{aligned}
$$

Equation (11) is the downward sloping demand function for good z. After combining it with (12), one gets the price index $P_{t}=\left[\int_{0}^{1} P_{Z, t}^{1-\mu}\right]^{\frac{1}{1-\mu}}$.

\subsection{Monetary policy}

The central bank sets the nominal interest rate following a Taylor rule

$$
\log R_{t}^{N}-\log R^{s s}=\theta^{\Pi} \log \pi_{t}
$$




\section{Results}

\subsection{The theoretical effect of LAMP on asset returns ${ }^{6}$}

The second order approximations to the steady state values for the riskless rate, $r^{R}=\frac{1}{V^{R}}$, and for the equity risk premium, $r^{p}$, are

$$
\begin{aligned}
r^{R}= & E \ln r_{t}^{R}=\ln \frac{1}{\beta}+(\sigma-\chi(\sigma-1)) g-\frac{\sigma^{2}}{2} \operatorname{var}_{c^{o}} \\
& +\frac{\theta \bar{n}^{\phi}(\sigma-1) \sigma}{1-\theta \bar{n}^{\phi}}\left(\operatorname{cov}_{c^{o}, n}-\frac{(\sigma-1)}{2 \sigma} \operatorname{var}_{n}\right) \\
r^{p}= & \frac{1}{\beta}\left(\sigma \operatorname{cov}_{c^{o}, r e q}-\frac{\theta \bar{n}^{\phi}}{1-\theta \bar{n}^{\phi}}(\sigma-1) \phi \operatorname{cov}_{n, r e q}\right)
\end{aligned}
$$

where $r^{p}=E\left[r_{t}^{e q}-r_{t}^{R}\right]$, and $v_{a r} c^{o}, \operatorname{cov}_{c^{o}, n}, \operatorname{var}_{n}, \operatorname{cov}_{c^{o}, r^{e q}}, \operatorname{cov}_{n, r} e q$ respectively define conditional moments of variables deviations from the deterministic steady state. ${ }^{78}$ Interpretation of (14) and (15) is straightforward and fully consistent with textbook asset pricing theory based on the stochastic discount factor approach. Thus variables $g$ and $v a r_{c^{o}}$ have opposite effects on $r^{R}$ because faster consumption growth induces Ricardian households to reduce their savings, whereas consumption volatility raises precautionary savings. An increase in the habit parameter delivers the standard result that savings grow ( $r^{R}$ falls) as long as habits raise the marginal utility of current consumption, i.e. $\sigma>1$. A positive value of $\operatorname{cov}_{c^{o}, r^{e q}}$ is obviously associated to a positive risk premium.

Finally, we look at the less familiar effects of employment on asset returns, due to the introduction of non-separability between consumption and leisure. From (2) it is easy to see that an increase in worked hours raises the marginal utility of consumption, $\lambda_{t}^{o}$. Thus an increase in $\operatorname{var}_{n}$ unambiguously raises the conditional expectation of $\lambda_{t}^{o}$, causing an increase in savings and a fall in $r^{R}$. The term $\operatorname{cov}_{c^{o}, n}$ has the opposite effect because a positive comovement between expected consumption and labor effort dampens the negative effect of expected consumption growth on $E_{t}\left\{\lambda_{t+1}^{o}\right\}$.A negative value for $\operatorname{cov}_{n, r^{e q}}$ raises $r^{p}$ because it lowers the covariance between $\lambda_{t+1}^{o}$ and $r_{t+1}^{e q}$.

Note that LAMP modifies the effect that volatility of macro variables has on asset returns:

\footnotetext{
${ }^{6}$ See Appendix A for a derivation of the results presented in this section.

${ }^{7}$ As discussed in section 3.2.1 below, we normalize $\theta$, so that $\bar{n}=1$. In this case we obtain $\frac{\theta \bar{n}^{\phi}}{1-\theta \bar{n}^{\phi}} \simeq 0.77$. Note that changing the normalization for steady state labor does not affect the above steady state ratio. With $\bar{n}=0.25$, for instance, we get again $\frac{\theta \bar{n}^{\phi}}{1-\theta \bar{n}^{\phi}} \simeq 0.77$.

${ }^{8}$ Variable $\bar{x}$ defines the value of $x$ in the deterministic steady state
} 


$$
\begin{gathered}
\operatorname{var}_{c^{o}}=\left(\frac{\bar{c}}{\overline{c^{o}}}\right)^{2} \operatorname{var}_{c}+\left(\frac{\psi}{1-\psi}\right)^{2}\left(\frac{\bar{d}}{\overline{c^{o}}}\right)^{2} \operatorname{var}_{d}+2\left(\frac{\bar{c}}{\overline{c^{o}}}\right)\left(\frac{\psi}{1-\psi}\right)\left(\frac{\bar{d}}{\overline{c^{o}}}\right) \operatorname{cov}_{c, d} \\
\operatorname{cov}_{c^{o}, n}=\left(\frac{\bar{c}}{\overline{c^{o}}}\right) \operatorname{cov}_{c, n}+\left(\frac{\psi}{1-\psi}\right)\left(\frac{\bar{d}}{\overline{c^{o}}}\right) \operatorname{cov}_{n, d} \\
\operatorname{cov}_{c^{o}, r e q}=\frac{\bar{c}}{\overline{c^{o}}} \operatorname{cov}_{c, r e q}+\frac{\psi}{1-\psi} \frac{\bar{d}}{\overline{c^{o}}} \operatorname{cov}_{d, r e q} \\
\text { where } \frac{\bar{c}}{\overline{c^{o}}}=1-\psi+\frac{1}{1+\frac{\bar{d}}{(1-\psi) \bar{w}}}, \frac{\bar{d}}{\overline{c^{o}}}=\frac{1-\psi}{\overline{\frac{w}{\bar{d}}}(1-\psi)+1}, \frac{\bar{d}}{\bar{w}}=\frac{\bar{d}}{\bar{w}}=\bar{n}\left[\frac{1-\alpha}{\alpha}-\frac{\delta \frac{1-\beta(1-\delta)}{\beta(1-\alpha)}\left(\frac{\mu}{\mu-1}\right)^{2}}{\alpha}\right]
\end{gathered}
$$

It is easy to see that an increase in $\psi$ unambiguously lowers the impact of consumption volatility and consumption-employment covariance, and raises the importance of dividends, whose effect on the consumption marginal utility of Ricardians is increasing in $\psi$.

To highlight differences between our approach and previous contributions such as De Graeve et al. (2010) we rearrange the equity premium as follows

$$
r^{p}=\frac{1}{\beta}\left(-\operatorname{cov}_{z, r e q}-\operatorname{cov}_{\lambda, r^{e q}}\right)
$$

where $z_{t}=\ln \lambda_{t}^{o}-\ln \lambda_{t} ; \lambda_{t}=(1-\psi) \lambda_{t}^{o}+\psi \lambda_{t}^{r t}$. In De Graeve et al (2010), prices are flexible and the labour contract is such that $\operatorname{cov}_{z, r e q}=0$ in the absence of exogenous redistributive shocks. To replicate the empirical risk premium it is therefore necessary to assume that redistributive shocks are negatively correlated with the productivity shock, which ensures that full risk sharing is precluded and the consumption marginal utility of workers falls with respect to the consumption marginal utility of firms owners.

\section{$3.2 \quad$ Numerical simulations}

Log-linearization is not well suited for analyzing risk premia, since it produces results characterized by certainty equivalence, where investors behave as if they were risk neutral and all assets have the same price. The literature has therefore relied on alternative solution methods. While global solution methods, such as value function iteration and projection methods, allow to take into account non-linearities, they are not able to deal with models with many state variables because they suffer from the curse of dimensionality. So, we shall solve the model using second order perturbation methods, as in Schmitt-Grohe and Uribe (2004). ${ }^{9}$

\subsubsection{Calibration}

The baseline calibration of the parameters is reported in Table 1. Following De Paoli et al (2010) we set the discount factor $\beta$ at $1 / 1.01$, the coefficient $\sigma$ at 5 , the quarterly capital depreciation rate $\delta$ at 0.025 and the Rotemberg parameters for wage and price stickiness at 77 , such that if a Calvo model was used instead, prices and nominal wage would be adjusted every 4.5 quarters. ${ }^{10}$ Following

\footnotetext{
${ }^{9}$ To solve the model we use the Dynare package.

${ }^{10}$ Such frequency is not far from estimates in the literature, see Colciago (2011) and Smets and Wouters (2007). Keen and Wang (2007) show how to convert a Calvo parameter into a Rotemberg parameter.
} 
De Graeve et al (2010) we set $\alpha=70 \%$ and the the Frisch elasticity at about $1.3 .^{11}$ Differently from De Graeve et al (2010) we assume that all agents have the same coefficient of relative risk aversion. The parameter for external habit formation $\chi$ is set to 0.7 , well in the range found in the empirical literature (see Dennis, 2009). Parameter $X^{K}$, crucial to introduce investment adjustment costs, is set at 0.23, as in Jermann (1998). As in Christiano et al (2005) and De Graeve et al (2010), fixed cost $f c$ represents the $20 \%$ of steady state output, therefore to obtain zero profits in the deterministic steady state we set $\mu=6$. We also set $\nu=6$, obtaining identical wage markups. Parameter $\theta$ is set such that hours are normalized to 1 in the deterministic steady state. The share of RT consumers is $40 \%$, within the range estimated in the literature reported in the introduction. As for the shock persistence parameters, we set $\rho_{\eta}=0.95$ (De Paoli et al., 2010) and $\rho_{\digamma}=0.73$ (Justiniano et al, 2010).The inflation parameter in the Taylor rule, $\theta^{\Pi}$, is equal to 1.5. Throughout, we assume a stationary economy, that is $g=0$.

\begin{tabular}{cc} 
Parameter & Value \\
\hline$\beta$ & $1 / 1.01$ \\
$\sigma$ & 5 \\
$\phi$ & 1 \\
$\theta$ & Such that $\bar{n}=1$ \\
$\chi$ & 0.7 \\
$\alpha$ & 0.7 \\
$X^{K}$ & 0.23 \\
$K$ & 77 \\
$X$ & 77 \\
$\delta$ & 0.025 \\
$\nu$ & 6 \\
$\mu$ & 6 \\
$\theta^{\Pi}$ & 1.5 \\
$a_{1}$ and $a_{2}$ & Such that capital adj cost is zero in steady state \\
$\psi$ & 0.4 \\
$f c$ & $\frac{1}{\mu-1} \bar{y}$ \\
$\rho_{\eta}$ & 0.95 \\
$\rho_{\digamma}$ & 0.73 \\
$\pi^{s s}$ & 1 \\
$g$ & 0 \\
\hline \hline
\end{tabular}

\subsection{Impulse response functions}

Figures 1 and 2 report the percentage response of some macroeconomic variables to $1 \%$ TFP and investment-specific shocks under both LAMP and full asset market participation. Figures 3 and 4 show the responses of agent specific consumption. The TFP shock produces an increase in output and consumption but a decrease in hours worked and in real marginal costs. Inflation falls as

\footnotetext{
${ }^{11}$ Notice that in the KPR case the Frisch elasticity is $\frac{1}{\phi\left(1+\frac{\theta \bar{n}_{s s}^{\phi}}{1-\theta \bar{n}_{s s}^{\phi}}\right)-1}$ while in the GHH case considered by De Graeve et al it is $\frac{1}{\phi-1}$. Given our calibration for $\bar{n}$ and $\theta$ we must set $\phi=1$.
} 
a consequence. The investment specific shock, instead, produces positive comovement between output, hours worked and real marginal costs. It is easy to see that for both shocks LAMP makes relatively little difference for output, aggregate consumption and worked hours, but we observe a relatively stronger response in investment and real marginal costs.
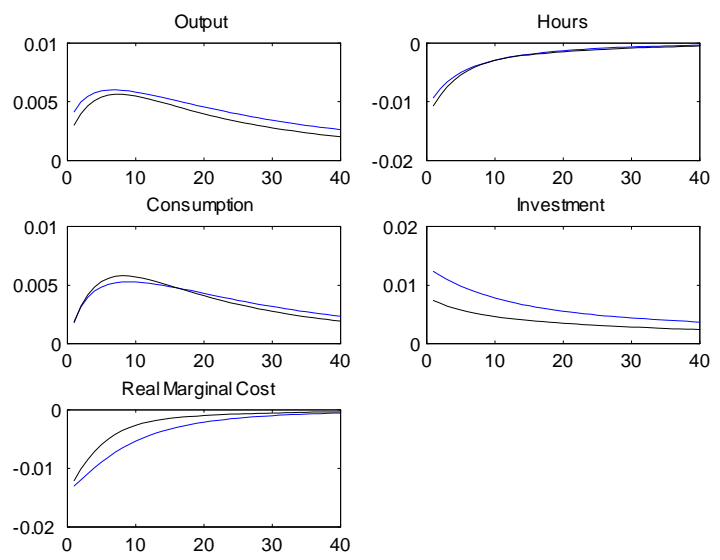

Figure 1: Percentage response to a TFP shock. Blue line: LAMP model. Black line: Representative agent model.
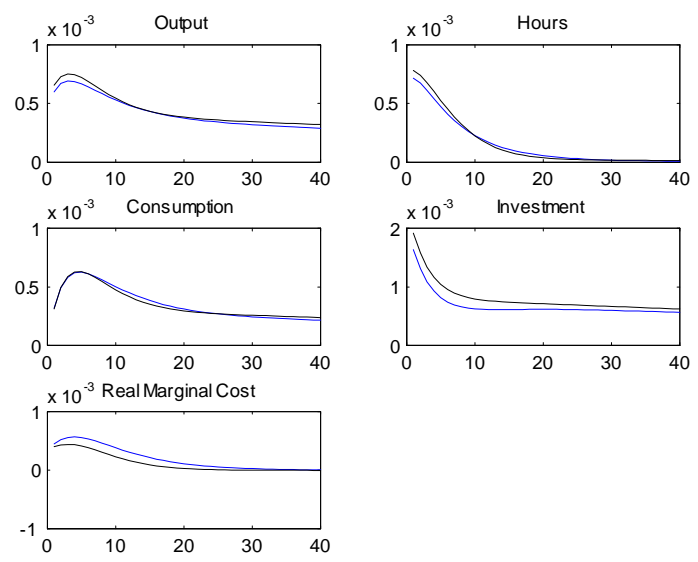

Figure 2: Percentage response to an investment specific shock. Blue line: LAMP model. Black line: Representative agent model. 


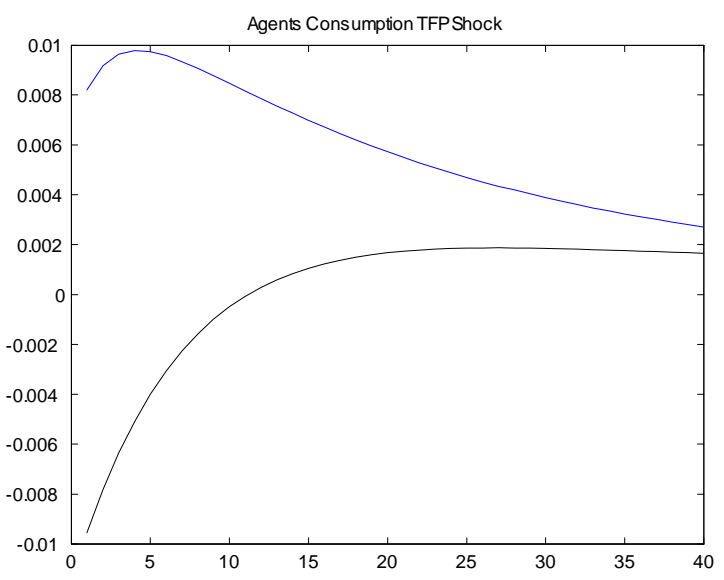

Figure 3: Percentage response to a TFP shock. Blue line: ricardian agents consumption. Black line: RT agents consumption.

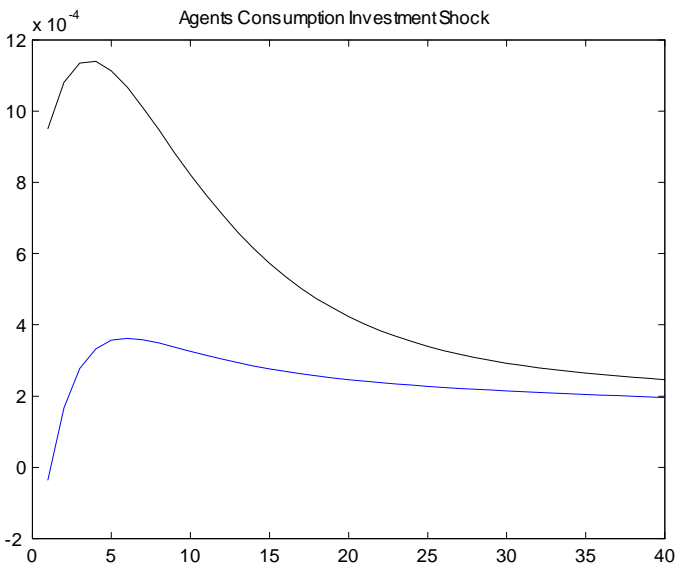

Figure 4: Percentage response to an investment specific shock. Blue line: ricardian agents consumption. Black line: RT agents consumption.

To understand these latter effects note that under full asset market participation the fall in labor demand, caused by price stickiness, is associated to a labor income reduction that is fully compensated for by the increase in firms profits. By contrast, under LAMP, the same labor income fall is associated to an income redistribution between Ricardians (whose income and consumption grow) and RTs, whose income and consumption fall. From eq.(2), (5), (6) and (8) it is easy to see that any increase in the dispersion of consumption marginal utilities has a disciplining effect on the real wage. As a consequence, under LAMP we observe a stronger reduction in labor income and in real marginal costs. Note that Ricardian households increase their investment in reaction to the favorable income redistribution caused by the shock. The investment-specific shock has exactly the opposite effect. Under LAMP the increase in labor demand has a stronger effect on the real wage and on real marginal costs. Due to price stickiness, the real wage rate entails an unfavorable 
income redistribution for Ricardian consumers, who are therefore induced to reduce investments.

In Figures 5 and 6 we plot IRFs for financial variables, that is, the real riskless rate, the real return on equity $r^{e q}$, the consumption value of the equity index, real dividends and the stochastic discount factor. It is easy to see that the TFP shock causes pro-cyclical movements of equity returns, while the investment specific shock makes stock returns move counter-cyclically. Under the representative agent model this implies that stocks require a premium for fluctuations linked to productivity but they insure the agent against fluctuations due to investment shocks. The premium linked to investment specific shocks is therefore negative, absent the effect of hours due to non-separability. As pointed out above, under LAMP the TFP shock causes an increase in savings and therefore a fall in the riskless rate. The stronger fall in real marginal costs is associated with a persistent increase in expected dividends. This, in turn, causes an overreaction of the equity index. LAMP unambiguously raises the positive correlation between Ricardian consumption and the return on equity caused by the TFP shock.

Following an investment specific shock, LAMP causes a stronger reaction of marginal costs that triggers a larger fall in dividends, in the equity index and in the return on equity. The consumption of Ricardian agents slightly falls at the moment of the shock and then increases less than aggregate consumption. In spite of consumption dynamics, the inverse relation between the stochastic discount factor and equity returns is now stronger, and LAMP makes sure that the investment shock commands a positive equity premium, even if smaller than that due to TFP shocks. ${ }^{12}$
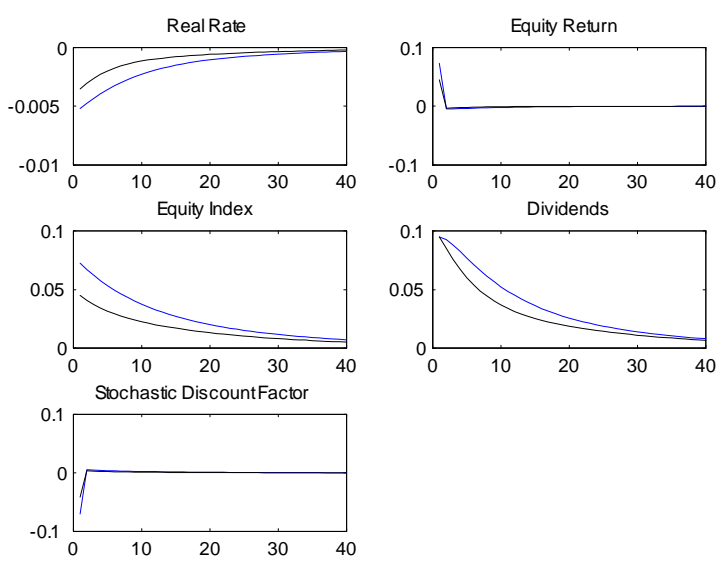

Figure 5: Percentage response to a TFP shock. Blue line: LAMP model. Black line: Representative agent model.

\footnotetext{
${ }^{12}$ This result is due to the effect of hours on consumption marginal utility. The contribution of the investmentspecific shock to the overall equity premium remains small (see our discussion below).
} 

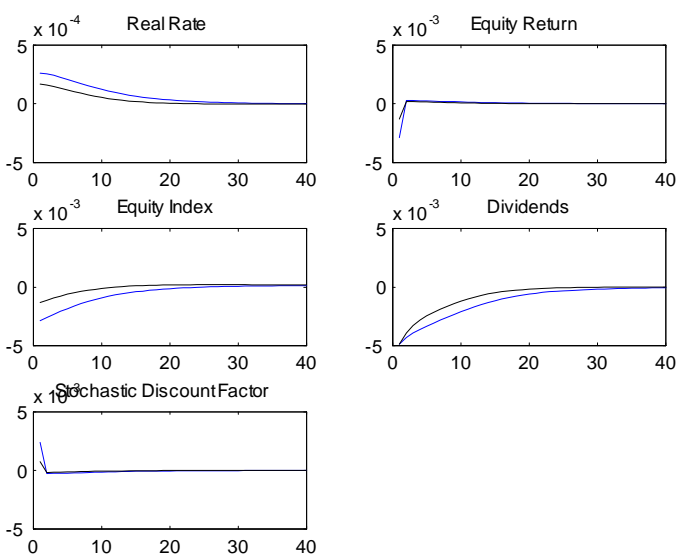

Figure 6: Percentage response to an investment specific shock. Blue line: LAMP model. Black line: Representative agent model.

Summarizing our results, introduction of the LAMP hypothesis seems to have a rather modest effect on aggregate variables such as output, hours, aggregate consumption. We do observe more important effects on real marginal costs and investment, due to the redistributive effects of the shocks. LAMP-induced income redistribution has important implications for financial variables: relative to full asset market participation, the correlation between Ricardian agents' consumption and equity return increases.

\subsection{Simulated macroeconomic and financial statistics}

Prediction of macroeconomic and financial variables requires that, in addition to the parameter values reported in Table 1 we calibrate standard deviations of TFP and investment specific shocks. We experiment with three different alternatives. In the benchmark case, we take $\sigma_{\eta}=0.01$ from De Paoli et al. (2010), and $\sigma_{\digamma}=0.06$ from Justiniano et al (2010). The second and the third alternatives are based on the Simulated Method of Moments (SMM henceforth), as presented in Ruge-Murcia (2012). The SMM approach consists in picking parameter values to minimize a loss function $L=g(b)^{T} W g(b)$ where $g(b)$ is a column vector containing the difference between simulated moments and data generated moments as a function of the parameters in vector $b$ and $W$ is a weighting matrix.

In the second calibration, vector $b$ contains the standard deviations $\sigma_{\eta}$ and $\sigma_{\digamma}$, which are selected in order to match US output growth volatility (about 1.06 on a quarterly basis) and the average yearly equity premium (about 5.1, as documented in Shiller (2013)) over the period 1950-2007.13 In the third experiment the share of RT consumers $\psi$ is endogeneized and included in $b$. In addition to the equity premium and output growth volatility, vector $g(b)$ includes the standard deviations of investment, consumption, and hours, the level and standard deviation of the riskless rate, the standard deviation of equity returns and the correlations of the latter with consumption and hours. Notice that our third exercise implements a grid search on $\psi, \sigma_{\eta}$ and $\sigma_{\digamma}$ such that observed values

\footnotetext{
${ }^{13}$ The data sources and the details of raw data transformations are described in the Appendix B.
} 
for $v r_{y}, r^{p}$ are obtained and the model fit of the other macroeconomic and financial statistics in $g(b)$ is maximized.

In table 2 we report shock standard deviation values. Note that when the SMM method is used to obtain an endogenous share of RT consumers we obtain $\psi \simeq 0.61$. Thus, for a DSGE model to match the risk premium the value $\psi$ is much larger than what is typically obtained in empirical DSGE models that neglect financial variables. ${ }^{14}$ Our calibrations of $\sigma_{\eta}$ are in the range usually considered in the literature (see Canova and Paustian (2011)). Our calibrations of $\sigma_{\digamma}$ are indeed larger than the estimates presented in Justiniano et al (2010), who consider a number of additional shocks. We also experimented with these other shocks, finding that their main contribution would be to match volatility of macroeconomic variables, with very limited effects on financial statistics. ${ }^{15}$ In a sense, the $\sigma_{\digamma}$ calibration adopted here proxies for the effects of these other shocks on the volatility of macroeconomic variables.

\begin{tabular}{ccc} 
& \multicolumn{2}{c}{ Shocks calibration } \\
\hline & $\sigma_{\eta}$ productivity shock & $\sigma_{\digamma}$ investment shock \\
Literature Calibration & 0.01 & 0.06 \\
SMM constrained $(\psi=0.4)$ & 0.0146 & 0.1421 \\
SMM unconstrained $(\psi \simeq 0.61)$ & 0.0085 & 0.1739 \\
\hline
\end{tabular}

Table 2 - Shocks standard deviation

\begin{tabular}{cccccccc} 
& $\sigma_{y}$ & $\frac{\sigma_{i n v}}{\sigma_{y}}$ & $\frac{\sigma_{c}}{\sigma_{y}}$ & $\frac{\sigma_{n}}{\sigma_{y}}$ & $\rho_{y, i n v}$ & $\rho_{y, c}$ & $\rho_{y, n}$ \\
\hline US data 1950-2007 & 1.06 & 2.88 & 0.77 & 1.98 & 0.7 & 0.81 & 0.89 \\
$\quad$ Model & & & & & & & \\
Literature Calibration $\psi=0.4$ & 0.56 & 2.86 & 0.61 & 1.89 & 0.93 & 0.89 & -0.35 \\
Literature Calibration $\psi=0$ & 0.52 & 2.68 & 0.68 & 2.32 & 0.90 & 0.89 & -0.16 \\
SMM constrained $\psi=0.4$ & 1.06 & 2.83 & 0.62 & 1.64 & 0.93 & 0.89 & 0.05 \\
SMM unconstrained $\psi=0.61$ & 1.06 & 2.75 & 0.65 & 1.25 & 0.92 & 0.9 & 0.53 \\
\hline \hline
\end{tabular}

Table 3 - All moments are quarterly. Data: see Appendix B.

\begin{tabular}{ccccccc} 
Unconditional moments & $E\left[R_{t+1}^{e q}-R_{t}^{R}\right]$ & $E R_{t}^{R}$ & $\sigma_{r^{r}}$ & $\sigma_{r^{e q}}$ & $\rho_{r^{e q}, c}$ & $\rho_{R^{e q}, n}$ \\
\hline $\begin{array}{c}\text { US data 1950-2007 } \\
\text { Model }\end{array}$ & 5.1 & 1.02 & 2.36 & 15.02 & 0.05 & -0.19 \\
Literature Calibration $\psi=0.4$ & 2.23 & 3.04 & 2.75 & 15.35 & 0.35 & -0.98 \\
Literature Calibration $\psi=0$ & 0.78 & 3.72 & 1.61 & 9.32 & 0.35 & -0.97 \\
$\quad$ SMM constrained $\psi=0.4$ & 5.1 & 1.76 & 4.29 & 23.39 & 0.11 & -0.96 \\
SMM unconstrained $\psi=0.61$ & 5.1 & 1.68 & 4.34 & 22.94 & -0.29 & -0.95 \\
\hline \hline
\end{tabular}

Table 4 - All moments are yearly. The standard deviations are 200 times the quarterly model concept.

Data: see Appendix B.

Under standard shock calibrations (experiment 1), LAMP allows to increase the equity premium from 0.78 to 2.23. Such an increase is notable, as the standard deviation of output is almost the same as under the representative agent model and half that of the data.

\footnotetext{
${ }^{14}$ As mentioned in the introduction, see Campbell and Mankiw (1990), Coenen and Straub (2005) and Forni, Monteforte, and Sessa (2009).

${ }^{15}$ Results available upon request.
} 
Consider now the SMM experiments. In the case where $\psi$ is constrained to be 0.4 the model behaves sufficiently well for what concerns most moments, but it overestimates the volatility of the riskless rate and of the equity return. The correlations of hours with output and equity returns appear to be the most difficult moments to match. The first is strongly positive in the data (0.89), while it is only 0.05 in the model. Table 5 , which reports the decomposition of output variance and of the equity premium, helps to get this point. The investment specific shock is the main determinant of output volatility, accounting for $65.6 \%$ of it, but its role is pretty small for what concerns the equity premium $(11.42 \%)$. The TFP shock is necessary to account for the equity premium, but since this shock produces a counterfactually negative correlation between worked hours and output, the latter statistic is difficult to match. In other words, replicating the equity premium and the correlation between hours and output at the same time is difficult because the TFP shock, which is crucial to fulfill the first task, obstacles the accomplishment of the second.

The correlation of hours with equity returns is negative in the data $(-0.19)$, but the model exaggerates this feature and produces a strongly negative correlation $(-0.96)$. Since both shocks tend to produce a negative covariance between the two variables, such difficulty should not surprise. Other shocks are probably needed to better match the latter statistics.

In our third experiment we obtain a strong enhancement of the model-implied correlation of hours with output, which grows from 0.05 to 0.53 . The ability to replicate other moments is not particularly affected, apart from a worsening of the fit of hours volatility, which goes from 1.64 to 1.25 and of the correlation of consumption with equity returns, which turns negative and falls from 0.1 to -0.29 . The reason for the relatively high value of $\psi$ is that a high share of RT consumers increases the income-redistribution effect of shocks and therefore raises the equity premium, while overall macroeconomic volatility is marginally affected. The higher value of $\psi$ allows to replicate the equity premium with a lower variance of the TFP shock, which in turn generates a better fit of hours-output correlation. The role of the investment specific shock in the economy is now larger. Its contribution to $v r_{y}$ and $r^{p}$ respectively amounts to $79.33 \%$ and $42.83 \%$. This bigger role of the investment specific shock has a cost, anyhow, which is due to the fact that aggregate consumption and stock returns respond in opposite directions and their correlation turns negative.

\begin{tabular}{ccccc} 
& Output Variance Decomposition & \multicolumn{2}{c}{ RP Decomposition } \\
\hline & TFP Shock & Investment Shock & TFP Shock & Investment Shock \\
Literature Calibration $\psi=0.4$ & 57.98 & 42.02 & 95.13 & 4.87 \\
Literature Calibration $\psi=0$ & 41.06 & 58.94 & 97.65 & 2.35 \\
SMM constrained $(\psi=0.4)$ & 34.40 & 65.60 & 88.58 & 11.42 \\
SMM unconstrained $(\psi \simeq 0.61)$ & 20.67 & 79.33 & 57.17 & 42.83 \\
\hline \hline
\end{tabular}

Table 5 - Output variance and equity premium decomposition

Table 6, 7 and 8 report respectively the decomposition of the equity premium in (15), the decomposition of the riskless rate in (14) and, again, the decomposition of the equity premium in (17). 


\begin{tabular}{cccc} 
& \multicolumn{1}{c}{$\frac{1}{\beta} \sigma \operatorname{cov}_{c^{o}, r} e q$} & $-\frac{1}{\beta} \frac{\theta \bar{n}^{\phi}}{1-\theta \bar{n}^{\phi}}(\sigma-1) \phi \operatorname{cov}_{n, r^{e q}}$ \\
\hline RP Decomposition & $\frac{1}{\beta} \sigma \frac{\bar{c}}{\overline{c^{o}}} \operatorname{cov}_{c, r}{ }^{e q}$ & $\frac{1}{\beta} \sigma \frac{\psi}{1-\psi} \frac{\bar{d}}{\overline{c^{o}}} \operatorname{cov}_{d, r e q}$ & \\
Literature Calibration $\psi=0.4$ & $9.04 \%$ & $47.11 \%$ & $43.85 \%$ \\
SMM constrained $(\psi=0.4)$ & $4.06 \%$ & $48.66 \%$ & $47.29 \%$ \\
SMM unconstrained $(\psi \simeq 0.61)$ & $-7.91 \%$ & $72.32 \%$ & $35.59 \%$ \\
\hline \hline
\end{tabular}

Table 6 - Percentage contributions to the equity premium.

\begin{tabular}{cccc} 
& $-\frac{\sigma^{2}}{2} \operatorname{var}_{c^{o}}$ & $\frac{\theta \bar{n}^{\phi}(\sigma-1) \sigma}{1-\theta \bar{n}^{\phi}} \operatorname{cov}_{c^{o}, n}$ & $-\frac{\theta \bar{n}^{\phi}(\sigma-1) \sigma}{1-\theta \bar{n}^{\phi}} \frac{(\sigma-1)}{2 \sigma} \operatorname{var}_{n}$ \\
\hline Riskless Rate Decomposition & & $44.56 \%$ & $24.34 \%$ \\
Literature Calibration $\psi=0.4$ & $31.10 \%$ & $42.15 \%$ & $28.95 \%$ \\
SMM constrained $(\psi=0.4)$ & $28.9 \%$ & $40.9 \%$ & $16.87 \%$ \\
SMM unconstrained $(\psi \simeq 0.61)$ & $42.23 \%$ & $0.96 \%$ \\
\hline \hline
\end{tabular}

Table 7a - Percentage contributions to the precautionary savings motive.

\begin{tabular}{cccc}
\multicolumn{3}{c}{$-\frac{\sigma^{2}}{2} \operatorname{var}_{c^{o}}$} \\
\hline Riskless Rate Decomp. & $-\frac{\sigma^{2}}{2}\left(\frac{\bar{c}}{\bar{c}^{o}}\right)^{2} \operatorname{var}_{c}$ & $-\frac{\sigma^{2}}{2}\left(\frac{\psi}{1-\psi}\right)^{2}\left(\frac{\bar{d}}{\bar{c}^{o}}\right)^{2} \operatorname{var}_{d}-\sigma^{2}\left(\frac{\bar{c}}{c^{o}}\right)\left(\frac{\psi}{1-\psi}\right)\left(\frac{\bar{d}}{\bar{c}^{o}}\right) \operatorname{cov}_{c, d}$ \\
Literature Calibration $\psi=0.4$ & $9.19 \%$ & $67.65 \%$ & $23.16 \%$ \\
SMM constrained $(\psi=0.4)$ & $16.69 \%$ & $77.06 \%$ & $6.25 \%$ \\
SMM unconstrained $(\psi \simeq 0.61)$ & $11.12 \%$ & $120.11 \%$ & $-31.23 \%$ \\
\hline \hline
\end{tabular}

Table $7 \mathrm{~b}$ - Percentage contributions to the term $-\frac{\sigma^{2}}{2} \operatorname{var}_{c^{o}}$

\begin{tabular}{ccc} 
& $\frac{\theta \bar{n}^{\phi}(\sigma-1) \sigma}{1-\theta \bar{n}^{\phi}} \operatorname{cov}_{c^{o}, n}$ \\
\hline Riskless Rate Decomp. & $\frac{\theta \bar{n}^{\phi}(\sigma-1) \sigma}{1-\theta \bar{n}^{\phi}}\left(\frac{\bar{c}}{\bar{c}^{o}}\right) \operatorname{cov}_{c, n}$ & $\frac{\theta \bar{n}^{\phi}(\sigma-1) \sigma}{1-\theta \bar{n}^{\phi}}\left(\frac{\psi}{1-\psi}\right)\left(\frac{\bar{d}}{\bar{c}^{o}}\right) \operatorname{cov}_{n, d}$ \\
Literature Calibration $\psi=0.4$ & $11.37 \%$ & $88.63 \%$ \\
SMM constrained $(\psi=0.4)$ & $-4.4 \%$ & $104.4 \%$ \\
SMM unconstrained $(\psi \simeq 0.61)$ & $-24.3 \%$ & $124.3 \%$ \\
\hline \hline
\end{tabular}

Table $7 \mathrm{c}$ - Percentage contributions to the term $\frac{\theta \bar{n}^{\phi}(\sigma-1) \sigma}{1-\theta \bar{n}^{\phi}} \operatorname{cov}_{c^{o}, n}$

\begin{tabular}{ccc} 
& $-\frac{1}{\beta} \operatorname{cov}_{\lambda, r e q}$ & $-\frac{1}{\beta} \operatorname{cov}_{z, r}{ }^{e q}$ \\
\hline RP Decomposition & & \\
Literature Calibration $\psi=0.4$ & $18.15 \%$ & $81.85 \%$ \\
SMM constrained $(\psi=0.4)$ & 14.79 & $85.21 \%$ \\
SMM unconstrained $(\psi \simeq 0.61)$ & $-16.2 \%$ & $116.2 \%$ \\
\hline \hline
\end{tabular}

Table 8 - Percentage contributions to the equity premium.

Under all calibrations, most of the predicted equity premium comes from agent-specific risks such as the covariance between dividends and equity returns. Another important component comes from the term concerning non separability between consumption and labor effort, whereas the influence of the covariance between aggregate consumption and equity returns is almost absent. The latter, indeed, contributes to the equity premium only for about $4 \%$ and $9 \%$ under the first two experiments, while with $\psi$ endogenous its effect turns negative $(-7.91 \%)$. The term $\operatorname{cov}_{d, r e q}$, that would not be present under full asset market participation, contributes for about a half of the 
equity premium in the first and second experiment and for $72.32 \%$ in the third one, confirming that redistribution is the main factor driving our results.

The contribution of consumption-labor non-separability falls when $\psi$ is endogeneized. This result can be well appreciated by considering the equity premium decomposition (17) (Table 8). In this case the equity premium is decomposed into two risk factors. The first one is the covariance between average marginal utility of consumption and equity returns. The second one is the risk due to fluctuations of the ratio between the marginal utility of Ricardians and average marginal utility $\left(\operatorname{cov}_{z, r e q}\right)$. Notice that the term $\operatorname{cov}_{z, r e q}$ would be equal to zero in the absence of redistribution or under perfect risk sharing as relative marginal utility would be constant. Hence, term $-\frac{1}{\beta} \operatorname{cov}_{z, r e q}$ measures the effect of redistribution on the equity premium. Such an effect is clearly dominant, indeed it always explains more than $80 \%$ of the equity premium, and its effect is even larger than $100 \%$ when $\psi$ is endogenous. ${ }^{16}$ Here we can also compare our results to De Graeve et al (2010). In their model, there is a labor contract that allows for perfect risk sharing between asset holders and non asset holders. In that case $z_{t}$ would be constant and $\operatorname{cov}_{z, r} e q=0$. To replicate the equity premium De Graeve et al (2010) have to introduce an exogenous shock to $z_{t}$, obtaining an estimated negative correlation between $z_{t}$ and the TFP shock. We can interpret our model as an endogeneization of the redistributive shocks.

\subsubsection{Precautionary savings and the riskless rate}

From Table 4 it is easy to see that under experiments 2 and 3 LAMP considerably lowers the predicted riskless rate, bringing it close to its observed value. Using (14) and (16) we highlight the determinants of the precautionary savings effect on the average riskless rate (Table 7 ). Precautionary savings are due to the conditional variance of Ricardian households consumption, the conditional variance of hours and the conditional covariance of their consumption with hours. In all experiments, the three motives are almost equally weighted, with the latter being less important when $\psi$ is endogenous. In addition, we decompose asset holders consumption variance in terms of aggregate consumption, dividends and covariance between the two. As can be observed, most of the consumption uncertainty depends on dividends volatility, which suggests the important role played by redistribution in increasing the precautionary saving motive and reducing the riskless rate.

\section{Sensitivity Analysis of the Model}

Tables 9 and 10 report the sensitivity of our result to variations in the habit parameter, in the Frisch elasticity, in the capital adjustment cost and in the Rotemberg parameters. In all experiments, we keep the literature calibration for shocks and for $\psi$.

\subsection{Nominal Rigidities}

When prices are flexible and only wages are sticky, the equity premium falls from 2.23 to 1.31 , notwithstanding a strong increase in output volatility ( $\sigma_{y}$ almost doubles). The model with flexible nominal wages and sticky prices, on the contrary, delivers almost the same premium of the benchmark model, even if the share of RT consumers is set to 0.2 to insure determinacy. Such statistics suggest that the fundamental nominal rigidity driving our results is price stickiness, not

\footnotetext{
${ }^{16}$ In this latter case the contribution of average marginal utility gets negative.
} 
wage stickiness. This is in sharp contrast with the previous finding that price stickiness decreases the premium in representative agent models (De Paoli et al., 2010).

Price rigidities make firms mark ups time varying and strenghten the redistributive effect of shocks. In their absence, mark-ups are constant and shocks trigger much less redistribution, which occurs as a consequence of variations in relative factor incomes. Consider for instance a positive TFP shock. Under price stickiness, the expansion in the productive capacity of firms does not imply a sudden fall of prices. As market demand does not absorb all the new productive potential at the rigid market price, firms cut worked hours. The fall in labor incomes causes a reduction of RT consumption, while firm margins and profits go up, increasing the welfare of Ricardian agents. Under flexible prices market demand absorbs all the new productive potential, worked hours do not fall and RT consumption grows along with that of Ricardians. The idiosyncratic non-insurable risk faced by Ricardians is limited to the variation in capital returns. This exercise therefore shows that LAMP can have a significant effect on the equity premium only if labor and capital income move in opposite directions, and that is the case only if prices are sticky. Notice that the redistributive effect of shocks is so important, that even if the overall volatility of the economy is larger when prices are flexible, the risk premium is in fact lower.

\begin{tabular}{cccccccc} 
& $\sigma_{y}$ & $\frac{\sigma_{i n v}}{\sigma_{y}}$ & $\frac{\sigma_{c}}{\sigma_{y}}$ & $\frac{\sigma_{n}}{\sigma_{y}}$ & $\rho_{y, \text { inv }}$ & $\rho_{y, c}$ & $\rho_{y, n}$ \\
\hline US data 1950-2007 & 1.06 & 2.88 & 0.77 & 1.98 & 0.7 & 0.81 & 0.89 \\
& \multicolumn{7}{c}{ Model } \\
Benchmark & 0.56 & 2.86 & 0.61 & 1.89 & 0.93 & 0.89 & -0.35 \\
$\chi=0$ & 1.11 & 1.51 & 0.86 & 0.97 & 0.99 & 0.99 & 0.29 \\
$X^{K}=0.5$ & 0.89 & 3.16 & 0.56 & 1.26 & 0.93 & 0.83 & 0.13 \\
$\phi=5$ & 0.70 & 2.47 & 0.7 & 1.15 & 0.92 & 0.93 & -0.57 \\
$K=0$ & 0.99 & 1.62 & 0.91 & 0.5 & 0.88 & 0.97 & -0.38 \\
$X=0 \& \psi=0.2$ & 0.52 & 2.99 & 0.62 & 2.05 & 0.92 & 0.85 & -0.42 \\
\hline \hline
\end{tabular}

Table 9 - All moments are quarterly. Data: see Appendix B.

\begin{tabular}{ccccccc} 
Unconditional moments & $E\left[R_{t+1}^{e q}-R_{t}^{R}\right]$ & $E R_{t}^{R}$ & $\sigma_{R^{R}}$ & $\sigma_{R^{e q}}$ & $\rho_{r^{e q}, c}$ & $\rho_{r^{e q}, n}$ \\
\hline $\begin{array}{c}\text { US data 1950-2007 } \\
\text { Model }\end{array}$ & 5.1 & 1.02 & 2.36 & 15.02 & 0.05 & -0.19 \\
Literature Calibration $\psi=0.4$ & 2.23 & 3.04 & 2.75 & 15.35 & 0.35 & -0.98 \\
$\chi=0$ & 2.39 & 2.85 & 2.57 & 15.22 & 0.54 & -0.62 \\
$X^{K}=0.5$ & 1.66 & 3.29 & 2.52 & 13.23 & -0.02 & -0.93 \\
$\phi=5$ & 3.03 & 2.72 & 3.29 & 18.19 & 0.72 & -0.96 \\
$K=0$ & 1.31 & 3.47 & 4.27 & 12 & 0.87 & -0.74 \\
$X=0 \& \psi=0.2$ & 2.18 & 3.16 & 3.1 & 15.95 & 0.32 & -0.99 \\
\hline \hline
\end{tabular}

Table 10 - All moments are yearly. The standard deviations are 200 times the quarterly model concept.

Data: see Appendix B.

\subsubsection{Consumption Habits}

Eliminating consumption habits from the model raises the equity premium. This is at odds with what usually found in the literature, where consumption habits are considered a useful tool to get an equity premium consistent with the data (Uhlig, 2007). Notice that this obtains because removing habits almost doubles output growth volatility. In addition, the volatility of investment 
falls strongly, while that of consumption grows. This is inconsistent with the data, where investment is much more volatile than consumption.

\subsubsection{Capital Adjustment Costs}

An increase of $\mathrm{X}^{K}$ to 0.5 corresponds to a reduction of real frictions on capital accumulation. As shown in the literature (Boldrin et al (2001), De Paoli et al (2010)), capital adjustment costs are fundamental to produce a relatively high equity premium. We confirm this result. Smaller capital adjustment costs allow Ricardian households to smooth consumption by adjusting the capital stock, which renders their investment in stocks less risky. The equity premium falls from 2.23 to 1.66 when $X^{K}$ grows from 0.23 to 0.5 . Still, LAMP allows to increase the equity premium with respect to the representative agent model. In fact the representative agent model generates an equity premium of 0.78 even when $\mathrm{X}^{K}$ is 0.23 . Notice that lower capital adjustment costs turn the output-hours correlation positive and could in principle help to fit macroeconomic data. On the other hand, such effect seems too costly from the point of view of the performance of the model for what concerns financial statistics.

\subsubsection{Frisch Elasticity}

An increase of $\phi$ to 5 corresponds to a reduction of Frisch elasticity to 0.21 , near to the value assumed in De Paoli et al (2010). ${ }^{17}$ The aggregate labour supply schedule is more rigid when $\phi$ increases. This tends to raise the equity premium, as agents cannot use hours to offset effects of shocks on consumption. On the other hand, a higher $\phi$ also increases output volatility, suggesting that at least part of the higher equity premium is due to a higher volatility of the overall economy. Moreover, a lower Frisch elasticity worsens the output-hours correlation.

\section{Conclusions}

We introduce LAMP in an otherwise standard DSGE model with real and nominal rigidities. Our findings are the following. The combination of LAMP and price stickiness is very useful to fit both macro and financial data. This result is driven by income redistribution following shocks. The consumption of financial market participants is much more volatile than aggregate consumption and more correlated with stock returns. This makes investment in firm shares very risky and provides a justification for the high equity premium found in the data. The model is able to account both for the equity premium and for the low correlation of aggregate consumption with equity returns. Further, the strong correlation between dividends and Ricardian households' consumption unambiguously increases precautionary savings and reduces the riskless rate.

We decompose the equity premium produced by the model in two factors. The first one refers to aggregate risk (measured by the correlation between equity returns and aggregate consumption and hours) whereas the second one refers to idiosyncratic non-insurable risk measured by the correlation between firm profits and equity returns, that is, risk determined by income redistribution. We find that aggregate risk always plays a minor role in shaping the risk premium, while redistribution accounts for the major part of it. In contrast with previous contributions, the fundamental nominal rigidity in our model is price stickiness, not wage stickiness (Uhlig (2007), De Graeve et al (2010)).

\footnotetext{
${ }^{17}$ This value is more consistent with micro estimates but it is at odds with macro estimates.
} 
We consider a TFP shock and an investment specific shock. We find that the TFP shock is the main driver of the equity premium, while the investment specific shock is necessary to replicate macroeconomic statistics. LAMP allows to extract a higher equity premium from a less volatile TFP shock. As a consequence, the investment-specific shock can be given more weight and macroeconomic data can be fitted more easily. Indeed, LAMP affects the response of aggregate variables to shocks only marginally, while its major effect concerns redistribution. The better fit of macroeconomic data obtained under LAMP comes from the bigger role played by the investment specific shock in the variance decomposition of output.

\section{References}

[1] Andrew B. Abel, 1988. "Asset Prices under Habit Formation and Catching up with the Joneses" The American Economic Review, Vol. 80, No. 2, Papers and Proceedings of the Hundred and Second Annual Meeting of the American Economic Association

[2] Bilbiie, Florin O., 2008. "Limited asset markets participation, monetary policy and (inverted) aggregate demand logic," Journal of Economic Theory, Elsevier, vol. 140(1), pages 162-196, May.

[3] Jules van Binsbergen \& Jesús Fernández-Villaverde \& Ralph S.J. Koijen \& Juan F. Rubio-Ramírez, 2010 "The Term Structure of Interest Rates in a DSGE Model with Recursive Preferences," NBER Working Papers 15890, National Bureau of Economic Research, Inc.

[4] Michele Boldrin \& Lawrence J. Christiano \& Jonas D. M. Fisher, 2001. "Habit Persistence, Asset Returns, and the Business Cycle," American Economic Review, American Economic Association, vol. 91(1), pages 149-166, March.

[5] Campbell, John Y \& Mankiw, N Gregory, 1990. "Permanent Income, Current Income, and Consumption," Journal of Business \& Economic Statistics, American Statistical Association, vol. 8(3), pages 265-79, July.

[6] Canova, Fabio \& Paustian, Matthias, 2011."Business cycle measurement with some theory," CEPR Discussion Papers 8364, C.E.P.R. Discussion Papers.

[7] Lawrence J. Christiano \& Martin Eichenbaum \& Charles L. Evans, 2005. "Nominal Rigidities and the Dynamic Effects of a Shock to Monetary Policy," Journal of Political Economy, University of Chicago Press, vol. 113(1), pages 1-45, February.

[8] Andrea Colciago, 2011. "Rule-of-Thumb Consumers Meet Sticky Wages," Journal of Money, Credit and Banking, Blackwell Publishing, vol. 43, pages 325-353, 03.

[9] De Graeve, Ferre \& Dossche, Maarten \& Emiris, Marina \& Sneessens, Henri \& Wouters, Raf, 2010 "Risk premiums and macroeconomic dynamics in a heterogeneous agent model," Journal of Economic Dynamics and Control, Elsevier, vol. 34(9), pages 1680-1699, September.

[10] Richard Dennis, 2009. "Consumption Habits in a New Keynesian Business Cycle Model," Journal of Money, Credit and Banking, Blackwell Publishing, vol. 41(5), pages 1015-1030, 08 
[11] De Paoli, Bianca \& Scott, Alasdair \& Weeken, Olaf, 2010. "Asset pricing implications of a New Keynesian model," Journal of Economic Dynamics and Control, Elsevier, vol. 34(10), pages 2056-2073, October.

[12] Dixit, Avinash K \& Stiglitz, Joseph E, 1977. "Monopolistic Competition and Optimum Product Diversity," American Economic Review, American Economic Association, vol. 67(3), pages 297-308, June.

[13] Epstein, Larry G \& Zin, Stanley E, 1989. "Substitution, Risk Aversion, and the Temporal Behavior of Consumption and Asset Returns: A Theoretical Framework," Econometrica, Econometric Society, vol. 57(4), pages 937-69, July.

[14] Forni, Lorenzo \& Monteforte, Libero \& Sessa, Luca, 2009. "The general equilibrium effects of fiscal policy: Estimates for the Euro area," Journal of Public Economics, Elsevier, vol. 93(3-4), pages 559-585, April.

[15] Francesco Furlanetto, Gisle J. Natvik, Martin Seneca, "Investment shocks and macroeconomic co-movement", Journal of Macroeconomics, Volume 37, September 2013, Pages 208216

[16] Jordi Galí \& J. David López-Salido \& Javier Vallés, 2007. "Understanding the Effects of Government Spending on Consumption," Journal of the European Economic Association, MIT Press, vol. 5(1), pages 227-270, 03.

[17] Greenwood, Jeremy \& Hercowitz, Zvi \& Huffman, Gregory W, 1988. "Investment, Capacity Utilization, and the Real Business Cycle," American Economic Review, American Economic Association, vol. 78(3), pages 402-17, June.

[18] Fatih Guvenen, 2009. "A Parsimonious Macroeconomic Model for Asset Pricing," Econometrica, Econometric Society, vol. 77(6), pages 1711-1750, November.

[19] Iacoviello, Matteo, 2004. "Consumption, house prices, and collateral constraints: a structural econometric analysis," Journal of Housing Economics, Elsevier, vol. 13(4), pages 304-320, December.

[20] Justiniano, Alejandro \& Primiceri, Giorgio E. \& Tambalotti, Andrea, 2010. "Investment shocks and business cycles," Journal of Monetary Economics, Elsevier, vol. 57(2), pages 132-145, March.

[21] Jermann, Urban J., 1998. "Asset pricing in production economies," Journal of Monetary Economics, Elsevier, vol. 41(2), pages 257-275, April.

[22] King, Robert G. \& Plosser, Charles I. \& Rebelo, Sergio T., 1988. "Production, growth and business cycles : I. The basic neoclassical model," Journal of Monetary Economics, Elsevier, vol. 21(2-3), pages 195-232.

[23] Martin Lettau, 2003. "Inspecting The Mechanism: Closed-Form Solutions For Asset Prices In Real Business Cycle Models," Economic Journal, Royal Economic Society, vol. 113(489), pages 550-575, 07 . 
[24] Mankiw, N. Gregory and Zeldes, Stephen P., 1991. "The consumption of stockholders and nonstockholders," Journal of Financial Economics, Elsevier, vol. 29(1), pages 97-112

[25] Mankiw, N. Gregory (2000) "The Savers-Spenders Theory of Fiscal Policy," American. Economic Review 90(2): 120-125

[26] Mehra, Rajnish \& Prescott, Edward C., 1985. "The equity premium: A puzzle," Journal of Monetary Economics, Elsevier, vol. 15(2), pages 145-161, March.

[27] Polkovnichenko, V.,2004, "Limited stock market participation and the equity premium." Finance Research Letters 1 (March), 24-34.

[28] Rotemberg, J.J. (1982), "Sticky prices in the United States," Journal of Political Economy, 90: $1187-1211$.

[29] Glenn D. Rudebusch \& Eric T. Swanson, 2012. "The Bond Premium in a DSGE Model with Long-Run Real and Nominal Risks," American Economic Journal: Macroeconomics, American Economic Association, vol. 4(1), pages 105-43, January.

[30] Schmitt-Grohe, Stephanie \& Uribe, Martin, 2004. "Solving dynamic general equilibrium models using a second-order approximation to the policy function," Journal of Economic Dynamics and Control, Elsevier, vol. 28(4), pages 755-775, January.

[31] Shiller Robert, "http://www.econ.yale.edu/ shiller/data.htm", 2013

[32] Frank Smets \& Rafael Wouters, 2007. "Shocks and Frictions in US Business Cycles: A Bayesian DSGE Approach," American Economic Review, American Economic Association, vol. 97(3), pages 586-606, June.

[33] Harald Uhlig, 2007. "Explaining Asset Prices with External Habits and Wage Rigidities in a DSGE Model," American Economic Review, American Economic Association, vol. 97(2), pages 239-243, May.

[34] Weil, Philippe, 1992. "Hand-to-mouth consumers and asset prices," European Economic Review, Elsevier, vol. 36(2-3), pages 575-583, April.

[35] Vissing-Jørgensen,A.,2002. "Limited asset market participation and the elasticity of intertemporal substitution." Journal of Political Economy 110,825-853.

\section{Appendices}

\subsection{Appendix A: Second order approximations to asset returns}

In this appendix, we derive the expressions for the riskless rate and the equity premium reported in the main text. Rearranging marginal utility of Ricardian agents' consumption yields

$$
\left(c_{t}^{o}\right)^{-\sigma} c_{t-1}^{\chi(\sigma-1)}\left(1-\theta n_{t}^{\phi}\right)^{1-\sigma}=\lambda_{t}^{o}
$$

To help in the computation that follows, it is useful to define the auxiliary variable $x_{t}=1-\theta n_{t}^{\phi}$ so that the marginal utility of consumption can be rewritten as $\lambda_{t}^{o}=\left(c_{t}^{o}\right)^{-\sigma} c_{t-1}^{\chi(\sigma-1)} x_{t}^{1-\sigma}$. 
A second order log-approximation ${ }^{18}$ of $x_{t}$ delivers:

$$
\widehat{x}_{t}=-\frac{\theta \bar{n}^{\phi}}{1-\theta \bar{n}^{\phi}} \phi \hat{n}_{t}-\frac{1}{2} \frac{\theta \bar{n}^{\phi}}{\left(1-\theta \bar{n}^{\phi}\right)^{2}} \phi^{2} \hat{n}_{t}^{2}
$$

Since marginal utility of consumption is multiplicative in the defined variables, its second order log-approximation is equal to the first order one, hence $\widehat{\lambda}_{t}^{o}=-\sigma \widehat{c_{t}^{o}}+\chi(\sigma-1) \widehat{c_{t-1}}+(1-\sigma) \widehat{x_{t}}$. So, substituting for $\widehat{x_{t}}$ we get:

$$
\widehat{\lambda}_{t}^{o}=-\sigma \widehat{c_{t}^{o}}+\chi(\sigma-1) \widehat{c_{t-1}}+(1-\sigma)\left[-\frac{\theta \bar{n}^{\phi}}{1-\theta \bar{n}^{\phi}} \phi \hat{n}_{t}-\frac{1}{2} \frac{\theta \bar{n}^{\phi}}{\left(1-\theta \bar{n}^{\phi}\right)^{2}} \phi^{2} \hat{n}_{t}^{2}\right]
$$

As a consequence, the second order log-approximation of the stochastic discount factor is:

$$
\widehat{s d f_{t}^{o}}=\widehat{\lambda}_{t}^{o}-\widehat{\lambda}_{t-1}^{o}=-\sigma \Delta \widehat{c_{t}^{o}}+\chi(\sigma-1) \Delta \widehat{c_{t-1}}+(1-\sigma)\left[-\frac{\theta \bar{n}^{\phi}}{1-\theta \bar{n}^{\phi}} \phi \Delta \hat{n}_{t}-\frac{1}{2} \frac{\theta \bar{n}^{\phi}}{\left(1-\theta \bar{n}^{\phi}\right)^{2}} \phi^{2} \Delta \hat{n}_{t}^{2}\right]
$$

, where for any generic variable $h, \Delta h_{t}=h_{t}-h_{t-1}$.

De Paoli et al (2010) show that the real rate can be expressed as: $\widehat{r}_{t}^{R}=-E_{t} \widehat{s d f_{t+1}^{O}}-\frac{1}{2} \operatorname{Var}_{t}$ $\widehat{s d f_{t+1}^{o}}$. The conditional expectation of the stochastic discount factor is simply:

$$
E_{t} \widehat{s d f_{t+1}^{o}}=-\sigma E_{t} \Delta \widehat{c_{t+1}^{o}}+\chi(\sigma-1) \Delta \widehat{c_{t}}+(1-\sigma)\left[-\frac{\theta \bar{n}^{\phi}}{1-\theta \bar{n}^{\phi}} \phi E_{t} \Delta \hat{n}_{t+1}-\frac{1}{2} \frac{\theta \bar{n}^{\phi}}{\left(1-\theta \bar{n}^{\phi}\right)^{2}} \phi^{2} E_{t} \Delta \hat{n}_{t+1}^{2}\right]
$$

The conditional variance is instead given by:

$\operatorname{Var}_{t} \widehat{s d f_{t+1}^{o}}=\sigma^{2} \operatorname{Var}_{t} \Delta \widehat{c_{t+1}^{o}}+\left[(1-\sigma) \frac{\theta \bar{n}^{\phi}}{1-\theta \bar{n}^{\phi}} \phi\right]^{2} \operatorname{Var}_{t} \Delta \hat{n}_{t+1}+2 \sigma(1-\sigma) \frac{\theta \bar{n}^{\phi}}{1-\theta \bar{n}^{\phi}} \phi \operatorname{Cov}_{t}\left(\Delta \widehat{c_{t+1}^{o}}, \Delta \hat{n}_{t+1}\right)$

So the real interest rate at time $t$ is:

$$
\begin{aligned}
\widehat{r}_{t}^{R}= & \sigma E_{t} \Delta \widehat{c_{t+1}^{o}}-\chi(\sigma-1) \Delta \widehat{c_{t}}-(1-\sigma)\left[-\frac{\theta \bar{n}^{\phi}}{1-\theta \bar{n}^{\phi}} \phi E_{t} \Delta \hat{n}_{t+1}-\frac{1}{2} \frac{\theta \bar{n}^{\phi}}{\left(1-\theta \bar{n}^{\phi}\right)^{2}} \phi^{2} E_{t} \Delta \hat{n}_{t+1}^{2}\right] \\
& -\frac{1}{2} \sigma^{2} \operatorname{Var}_{t} \Delta \widehat{c_{t+1}^{o}}-\frac{1}{2}\left[(1-\sigma) \frac{\theta \bar{n}^{\phi}}{1-\theta \bar{n}^{\phi}} \phi\right]^{2} \operatorname{Var}_{t} \Delta \hat{n}_{t+1}-\sigma(1-\sigma) \frac{\theta \bar{n}^{\phi}}{1-\theta \bar{n}^{\phi}} \phi \operatorname{Cov}_{t}\left(\Delta \widehat{c_{t+1}^{o}}, \Delta \hat{n}_{t+1}\right)
\end{aligned}
$$

Taking the unconditional expectations of the latter expression, using the law of iterated expectations and noting that $E \hat{n}_{t+1}^{2}=E \hat{n}_{t}^{2}$, we get the average (stochastic steady state) riskless rate:

$$
\begin{aligned}
E \widehat{r}_{t}^{R}= & (\sigma-\chi(\sigma-1)) g-\frac{1}{2} \sigma^{2} E \operatorname{Var}_{t} \Delta \widehat{c_{t+1}^{o}} \\
& +\frac{\theta \bar{n}^{\phi}(\sigma-1) \sigma \phi}{1-\theta \bar{n}^{\phi}}\left(\operatorname{ECov}_{t}\left(\Delta \widehat{c_{t+1}^{o}}, \Delta \hat{n}_{t+1}\right)-\frac{(\sigma-1)}{2 \sigma} \frac{\theta \bar{n}^{\phi} \phi}{1-\theta \bar{n}^{\phi}} \operatorname{EVar}_{t} \Delta \hat{n}_{t+1}\right)
\end{aligned}
$$

\footnotetext{
${ }^{18}$ From now on, log-deviations from the deterministic steady state are expressed with a hat.
} 
In the main text we define the conditional (co)variances of any variables $h, j$ evaluated at the stochastic steady state $\operatorname{ECov}_{t}\left(h_{t+1}, j_{t+1}\right)\left(E \operatorname{Var}_{t}\left(h_{t+1}\right)\right)$ as $\operatorname{cov}_{h, j}\left(\operatorname{var}_{h}\right)$. Notice that up to a second order conditional second moments are constant, hence $\operatorname{Var}_{t}\left(h_{t+1}\right)=\operatorname{var}_{h} \forall t$ and $\operatorname{Cov}_{t}\left(h_{t+1}, j_{t+1}\right)=\operatorname{cov}_{h, j} \forall t$. Rearranging terms we get:

$$
\begin{gathered}
E \ln r_{t}^{R}=\ln \frac{1}{\beta}+(\sigma-\chi(\sigma-1)) g-\frac{\sigma^{2}}{2} \operatorname{var}_{c^{o}} \\
+\frac{\theta \bar{n}^{\phi}(\sigma-1) \sigma \phi}{1-\theta \bar{n}^{\phi}}\left(\operatorname{cov}_{c^{o}, n}-\frac{\theta \bar{n}^{\phi}(\sigma-1) \phi}{2 \sigma\left(1-\theta \bar{n}^{\phi}\right)} v a r_{n}\right)
\end{gathered}
$$

which is the expression reported in the main text.

The second order approximation of the equity premium can be expressed as

$$
r p_{t}=E_{t} r_{t+1}^{e q}-r_{t}^{R}=\frac{1}{\beta}\left(E_{t}\left[\widehat{r}_{t+1}^{e q}\right]-\widehat{r}_{t}^{R}+\frac{1}{2} \operatorname{Var}_{t}\left(\widehat{r}_{t+1}^{e q}\right)\right)=-\frac{1}{\beta} \operatorname{Cov}_{t}\left(\widehat{s d f}_{t+1}^{o}, \widehat{r}_{t+1}^{e q}\right)
$$

Since the covariance between equity returns and the stochastic discount factor is $-\sigma \operatorname{Cov}_{t}\left(\widehat{c}_{t+1}^{o}, \widehat{r}_{t+1}^{e q}\right)-$ $(1-\sigma) \phi \frac{\theta \bar{n}^{\phi}}{1-\theta \bar{n}^{\phi}} \operatorname{Cov}_{t}\left(\hat{n}_{t+1}, \widehat{r}_{t+1}^{e q}\right)$, we get:

$$
r p_{t}=\frac{1}{\beta}\left(\sigma \operatorname{Cov}_{t}\left(\widehat{c}_{t+1}^{o}, \widehat{r}_{t+1}^{e q}\right)+(1-\sigma) \phi \frac{\theta \bar{n}^{\phi}}{1-\theta \bar{n}^{\phi}} \operatorname{Cov}_{t}\left(\hat{n}_{t+1}, \widehat{r}_{t+1}^{e q}\right)\right)
$$

Again, making the same assumption we made while deriving the riskless rate and taking unconditional expectations, we can rewrite the above as in the main text:

$$
r p=r^{e q}-r^{R}=\frac{1}{\beta}\left(\sigma \operatorname{cov}_{c^{o}, r^{e q}}-(\sigma-1) \phi \frac{\theta \bar{n}^{\phi}}{1-\theta \bar{n}^{\phi}} \operatorname{cov}_{n, r^{e q}}\right)
$$

where $r^{e q}=E r_{t}^{e q}$ and $r^{R}=E r_{t}^{R}$.

In order to re-express everything in terms of aggregate variables, consider the budget constraint of the representative Ricardian household (eq. 4) and aggregate consumption

$$
c_{t}=(1-\psi) c_{t}^{o}+\psi c_{t}^{r t}=w_{t} n_{t}+d_{t}
$$

Then, take the difference between Ricardian agents' consumption and aggregate consumption, namely

$$
c_{t}^{o}-c_{t}=\frac{d_{t}}{1-\psi}-d_{t}
$$

Rearranging the equation, one gets

$$
c_{t}^{o}=c_{t}+\frac{\psi}{1-\psi} d_{t}
$$

Finally, we take the loglinear approximation of the above expression, which delivers

$$
\widehat{c}_{t}^{o}=\frac{\bar{c}}{\overline{c^{o}}} \widehat{c}_{t}+\frac{\psi}{1-\psi} \frac{\bar{d}}{\overline{c^{o}}} \widehat{d}_{t}
$$


From the latter expression, one can get:

$$
\begin{aligned}
& \operatorname{var}_{c^{o}}=\left(\frac{\bar{c}}{\overline{c^{o}}}\right)^{2} \operatorname{var}_{c}+\left(\frac{\psi}{1-\psi}\right)^{2}\left(\frac{\bar{d}}{\overline{\overline{c^{o}}}}\right)^{2} \operatorname{var}_{d}+2\left(\frac{\overline{\bar{c}}}{\overline{c^{\circ}}}\right)\left(\frac{\psi}{1-\psi}\right)\left(\frac{\bar{d}}{\overline{\bar{c}}}\right) \operatorname{cov}_{c, d} \\
& \operatorname{cov}_{c^{o}, n}=\left(\frac{\bar{c}}{\overline{c^{o}}}\right) \operatorname{cov}_{c, n}+\left(\frac{\psi}{1-\psi}\right)\left(\frac{\bar{d}}{\overline{\bar{c}}}\right) \operatorname{cov}_{n, d}
\end{aligned}
$$

and:

$$
\begin{aligned}
& r p=r^{e q}-r^{R}=\frac{1}{\beta}\left(\sigma \operatorname{cov}_{c^{o}, r^{e q}}-\phi \frac{\theta \bar{n}^{\phi}}{1-\theta \bar{n}^{\phi}}(\sigma-1) \operatorname{cov}_{n, r^{e q}}\right)= \\
& \frac{\sigma}{\beta}\left(\frac{\bar{c}}{\overline{c^{\circ}}} \operatorname{cov}_{c, r e q}+\frac{\psi}{1-\psi} \frac{\bar{d}}{\overline{c^{o}}} \operatorname{cov}_{d, r^{e q}}-\phi \frac{\theta \bar{n}^{\phi}}{1-\theta \bar{n}^{\phi}} \frac{(\sigma-1)}{\sigma} \operatorname{cov}_{n, r^{e q}}\right)
\end{aligned}
$$

To obtain the decomposition of the equity premium in equation (17) define optimizers relative marginal utility $\left(z_{t}=\frac{\lambda_{t}^{o}}{\lambda_{t}}\right)$ and take $\operatorname{logs}\left(z_{t}=\lambda_{t}^{o}-\lambda_{t}\right)$. The equity premium can be expressed as $r p_{t}=\frac{1}{\beta}\left(-\operatorname{Cov}_{t}\left(\widehat{z}_{t+1}, \widehat{r}_{t+1}^{e q}\right)-\operatorname{Cov}_{t}\left(\widehat{\lambda}_{t+1}, \widehat{r}_{t+1}^{e q}\right)\right)$, which unconditionally becomes:

$$
r p=\frac{1}{\beta}\left(-\operatorname{cov}_{z, r e q}-\operatorname{cov}_{\lambda, r e q}\right)
$$

The latter expression is the one reported in the main text.

\subsection{Appendix B: Data and SMM Procedure}

From the FRED database we took the dataset for aggregate consumption, output, investment and the price index. Consumption is Real Personal Consumption Expenditures, output is Real Gross Domestic Product while the price index is the Implicit Price Deflator. The latter has level 100 in 2005, while the first two are measured in billions of 2005 dollars. For investment we used Private Nonresidential Fixed Investment, which is in nominal terms and we transformed it to real terms dividing the series by the corresponding price index. All series contain annualized de-seasoned quarterly values.

The data for hours were taken from the Bureau of Labour Statistics database. Hours are Total Hours in Manufacturing and are collected at an annual frequency. Data on stock returns and the real riskless rate are taken from Robert Shiller's website and are also collected at annual frequency. As some of the series are quarterly and others yearly, we transformed the quarterly time series to yearly by summing over the quarters of each year and dividing by four, as the quarterly values are annualized at the source. Since the time unit of the model is a quarter, the SMM estimation was run by annualizing properly the model moments. The values reported in the main text were then transformed back to quarterly, where so indicated. In order to stationarize the series, we took the natural logarithm of the growth ratios for all variables apart from the equity return and the riskless rate. For the latter two variables we took the natural logarithm of the gross returns. The same procedure was applied to the simulated variables.

The standard deviations of the two shocks for the constrained estimation were obtained by minimizing $L=g(b)^{T} W g(b),{ }^{19}$ where $g(b)=g\left(\sigma_{\eta}, \sigma_{\digamma}\right)=$

\footnotetext{
${ }^{19}$ To minimise $L$ we use the fmincon function in MatLab with a interior point algorithm and a tolerance value equal to $1 e^{-5}$.
} 


$$
\left[\begin{array}{c}
\frac{1}{57} \sum_{t=1951}^{2007}\left(\ln \frac{y_{t}}{y_{t-1}}\right)^{2}-E\left(\ln \frac{y\left(\sigma_{\eta}, \sigma_{\digamma}\right)_{t}}{y\left(\sigma_{\eta}, \sigma_{\digamma}\right)_{t-1}}\right)^{2} \\
\frac{1}{57} \sum_{t=1951}^{2007}\left\{\ln \left(1+r_{t}^{e q}\right)-\ln \left(1+r_{t}^{r}\right)\right\}-E\left\{\ln \left(1+r\left(\sigma_{\eta}, \sigma_{\digamma}\right)_{t}^{e q}\right)-\ln \left(1+r\left(\sigma_{\eta}, \sigma_{\digamma}\right)_{t}^{r}\right)\right\}
\end{array}\right] \text { and } W
$$

is a $2 \times 2$ identity matrix. Notice that $\ln \frac{y_{t}}{y_{t-1}}$ was demeaned before the estimation and so $\frac{1}{57} \sum_{t=1951}^{2007}\left(\ln \frac{y_{t}}{y_{t-1}}\right)^{2}$

is the variance of the sample. $E\left(\ln \frac{y\left(\sigma_{\eta}, \sigma_{\digamma}\right)_{t}}{y\left(\sigma_{\eta}, \sigma_{\digamma}\right)_{t-1}}\right)^{2}$ and $E\left\{\ln \left(1+r\left(\sigma_{\eta}, \sigma_{\digamma}\right)_{t}^{e q}\right)-\ln \left(1+r\left(\sigma_{\eta}, \sigma_{\digamma}\right)_{t}^{r}\right)\right\}$ can be obtained as theoretical moments since we use a second order approximation or obtained through simulation, in which case they are estimated as $\frac{1}{\tau * 57} \sum_{t=1}^{\tau * 57}\left(\ln \frac{y\left(\sigma_{\eta}, \sigma_{\digamma}\right)_{t}}{y\left(\sigma_{\eta}, \sigma_{\digamma}\right)_{t-1}}\right)^{2}$ and $\frac{1}{\tau * 57} \sum_{t=1}^{\tau * 57}\left\{\ln \left(1+r\left(\sigma_{\eta}, \sigma_{\digamma}\right)_{t}^{e q}\right)-\ln \left(1+r\left(\sigma_{\eta}, \sigma_{\digamma}\right)_{t}^{r}\right)\right\}$ where $\tau * 57$ is the simulation lenght. The two approaches deliver almost the same results. In the unconstrained case, $g(b)=g\left(\sigma_{\eta}, \sigma_{\digamma}, \psi\right)=$ 


$$
\begin{aligned}
& \frac{1}{57} \sum_{t=1951}^{2007}\left(\ln \frac{n_{t}}{n_{t-1}}\right)^{2}-E\left(\ln \frac{n\left(\sigma_{\eta}, \sigma_{\digamma}, \psi\right)_{t}}{n\left(\sigma_{\eta}, \sigma_{\digamma}, \psi\right)_{t-1}}\right)^{2} \\
& \frac{1}{57} \sum_{t=1951}^{2007} \ln \frac{n_{t}}{n_{t-1}} \ln \left(1+r_{t}^{e q}\right)-E\left(\ln \frac{n\left(\sigma_{\eta}, \sigma_{\digamma}, \psi\right)_{t}}{n\left(\sigma_{\eta}, \sigma_{\digamma}, \psi\right)_{t-1}} \ln \left(1+r\left(\sigma_{\eta}, \sigma_{\digamma}, \psi\right)_{t}^{e q}\right)\right) \\
& \frac{1}{57} \sum_{t=1951}^{2007} \ln \frac{n_{t}}{n_{t-1}} \ln \frac{y_{t}}{y_{t-1}}-E\left(\ln \frac{n\left(\sigma_{\eta}, \sigma_{\digamma}, \psi\right)_{t}}{n\left(\sigma_{\eta}, \sigma_{\digamma}, \psi\right)_{t-1}} \ln \frac{y\left(\sigma_{\eta}, \sigma_{\digamma}, \psi\right)_{t}}{y\left(\sigma_{\eta}, \sigma_{\digamma}, \psi\right)_{t-1}}\right) \\
& \frac{1}{57} \sum_{t=1951}^{2007}\left(\ln \left(1+r_{t}^{e q}\right)\right)^{2}-E\left(\ln \left(1+r\left(\sigma_{\eta}, \sigma_{\digamma}, \psi\right)_{t}^{e q}\right)\right)^{2} \\
& \frac{1}{57} \sum_{t=1951}^{2007} \ln \frac{c_{t}}{c_{t-1}} \ln \left(1+r_{t}^{e q}\right)-E\left(\ln \frac{c\left(\sigma_{\eta}, \sigma_{\digamma}, \psi\right)_{t}}{c\left(\sigma_{\eta}, \sigma_{\digamma}, \psi\right)_{t-1}} \ln \left(1+r\left(\sigma_{\eta}, \sigma_{\digamma}, \psi\right)_{t}^{e q}\right)\right) \\
& \frac{1}{57} \sum_{t=1951}^{2007}\left(\ln \left(1+r_{t}^{r}\right)\right)^{2}-E\left(\ln \left(1+r\left(\sigma_{\eta}, \sigma_{\digamma}, \psi\right)_{t}^{r}\right)\right)^{2} \\
& \frac{1}{57} \sum_{t=1951}^{2007}\left(\ln \frac{y_{t}}{y_{t-1}}\right)^{2}-E\left(\ln \frac{y\left(\sigma_{\eta}, \sigma_{\digamma}, \psi\right)_{t}}{y\left(\sigma_{\eta}, \sigma_{\digamma}, \psi\right)_{t-1}}\right)^{2} \\
& \frac{1}{57} \sum_{t=1951}^{2007} \ln \frac{i n v_{t}}{i n v_{t-1}} \ln \frac{y_{t}}{y_{t-1}}-E\left(\ln \frac{i n v\left(\sigma_{\eta}, \sigma_{\digamma}, \psi\right)_{t}}{i n v\left(\sigma_{\eta}, \sigma_{\digamma}, \psi\right)_{t-1}} \ln \frac{y\left(\sigma_{\eta}, \sigma_{\digamma}, \psi\right)_{t}}{y\left(\sigma_{\eta}, \sigma_{\digamma}, \psi\right)_{t-1}}\right) \\
& \frac{1}{57} \sum_{t=1951}^{2007} \ln \frac{c_{t}}{c_{t-1}} \ln \frac{y_{t}}{y_{t-1}}-E\left(\ln \frac{c\left(\sigma_{\eta}, \sigma_{\digamma}, \psi\right)_{t}}{c\left(\sigma_{\eta}, \sigma_{\digamma}, \psi\right)_{t-1}} \ln \frac{y\left(\sigma_{\eta}, \sigma_{\digamma}, \psi\right)_{t}}{y\left(\sigma_{\eta}, \sigma_{\digamma}, \psi\right)_{t-1}}\right) \\
& \frac{1}{57} \sum_{t=1951}^{2007}\left(\ln \frac{i n v_{t}}{i n v_{t-1}}\right)^{2}-E\left(\ln \frac{i n v\left(\sigma_{\eta}, \sigma_{\digamma}, \psi\right)_{t}}{i n v\left(\sigma_{\eta}, \sigma_{\digamma}, \psi\right)_{t-1}}\right)^{2} \\
& \frac{1}{57} \sum_{t=1951}^{2007}\left(\ln \frac{c_{t}}{c_{t-1}}\right)^{2}-E\left(\ln \frac{c\left(\sigma_{\eta}, \sigma_{\digamma}, \psi\right)_{t}}{c\left(\sigma_{\eta}, \sigma_{\digamma}, \psi\right)_{t-1}}\right)^{2} \\
& \frac{1}{57} \sum_{t=1951}^{2007}\left\{\ln \left(1+r_{t}^{e q}\right)-\ln \left(1+r_{t}^{r}\right)\right\}-E\left\{\ln \left(1+r\left(\sigma_{\eta}, \sigma_{\digamma}, \psi\right)_{t}^{e q}\right)-\ln \left(1+r\left(\sigma_{\eta}, \sigma_{\digamma}, \psi\right)_{t}^{r}\right)\right\} \\
& \frac{1}{57} \sum_{t=1951}^{2007} \ln \left(1+r_{t}^{r}\right)-E \ln \left(1+r\left(\sigma_{\eta}, \sigma_{\digamma}, \psi\right)_{t}^{r}\right)
\end{aligned}
$$

All variables were demeaned before estimation. The weighting matrix is such that a very high loss is associated to deviating from the perfect fit of output volatility and of the equity premium, while other moments were weighted equally. In practice, $W$ is a diagonal matrix, with all diagonal entries equal to one apart from $W(7,7)$ and $W(12,12)$ which we set to 10000 . 